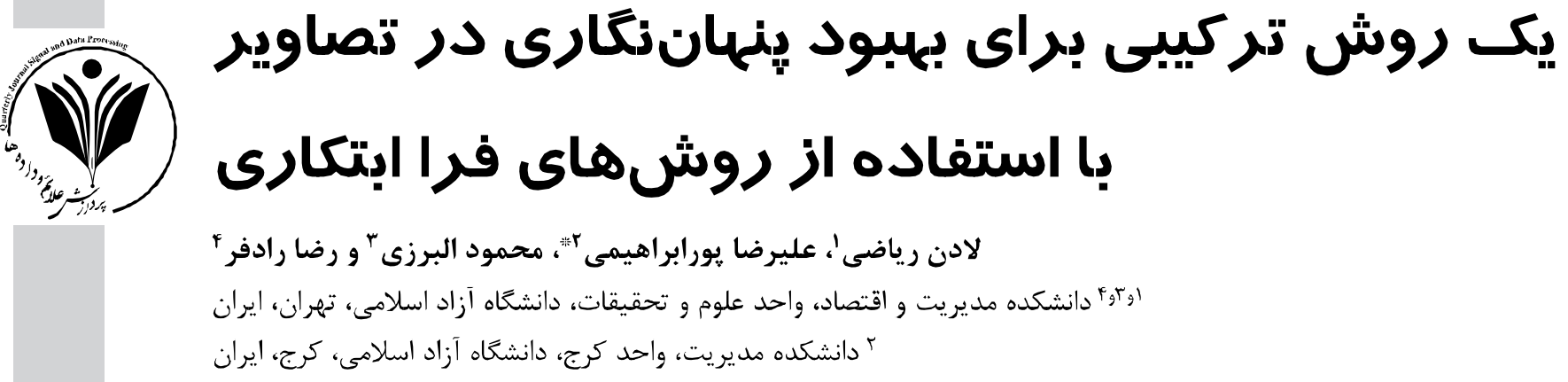

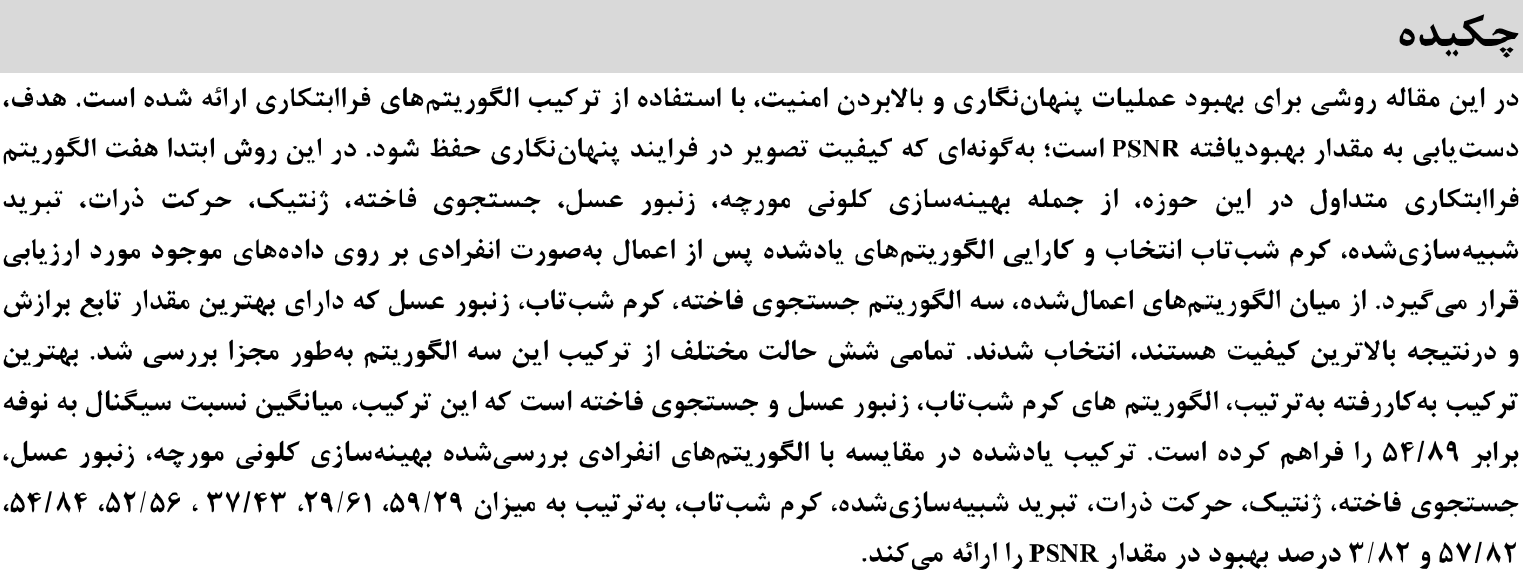

وازَّان كليدى: هنهماننكارى، الكَوريتههاى فرا ابتكارى، الكوريتهم كرم شبتاب، الكوريتم زنبور عسل، الكوريتم جستجوى فاخته.

\title{
A hybrid method to improve Steganography in JPEG images using metaheuristic algorithms
}

\author{
Ladan Riazi ${ }^{1}$, Alireza Pourebrahimi ${ }^{2 *}$, Mahmood Alborzi $^{3} \&$ Reza Radfar $^{4}$ \\ 1,3.4 faculty of economics and management, science and Research Branch, Islamic Azad \\ University, Tehran, Iran \\ ${ }^{2}$ faculty of management, Karaj Branch, Islamic Azad University, Karaj, Iran
}

\begin{abstract}
This paper presents a method for improving steganography and enhancing the security using combinatorial Meta-heuristic algorithms. The goal is to achieve an improved PSNR value in order to preserve the image quality in the steganography process.

Steganography algorithms, in order to insert message signal information inside the host data, create small changes based on the message signal in the host data, so that they are not visible to the human eye. Each cryptographic algorithm has two steps: insert a stego signal and extract it. You can use the area of the spatial or transformation area to insert the stego signal. Extraction can be done using the correlation with the original watermark or independently of it. Clearly, the choice of insertion method and how to extract are interdependent. In spatial techniques, information is stored directly in pixel color intensity but in the transform domain, the image is initially converted to another domain (such as frequency), and then the
\end{abstract}

* Corresponding author

*نويسندة عهدهدار مكاتبات

سال

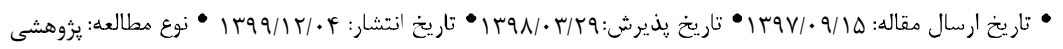


information is embedded in the conversion coefficients. Using optimization algorithms based on Metahuristic algorithms in this field is widely used and many researchers have been encouraged to use it. Using a suitable fitness function, these methods are useful in the design of steganography algorithms.

In this research, seven commonly used Metahuristic algorithms, including ant colony, bec, cuckoo search, genetics, Particle Swarm Optimization, Simulated Annealing and firefly were selected and the performance of these algorithms is evaluated individually on existing data after being applied individually.

Among the applied algorithms, cuckoo search, firefly and bee algorithms that have the best fitness function and therefore the highest quality were selected. All 6 different modes of combining these 3 algorithms were separately examined. The best combination is the firefly, bee and cuckoo search algorithms, which provides a mean signal-to-noise ratio of 54.89 .

The proposed combination compared to the individual algorithms of optimization of ant colony, bee, cuckoo search, genetics, Particle Swarm Optimization, Simulated Annealing and firefly, provides 59.29, 29.61, 37.43, 52.56, 54.84, 57.82, and 3.82\% improvement in the PSNR value.

Keywords: steganography, Metahuristic algorithms, firefly algorithm, bee algorithm, cuckoo search algorithms.

$$
\begin{aligned}
& \text { رنت ييكسلها دخيره مىشوند؛ ولى در حوزة تبديل ابتدا }
\end{aligned}
$$

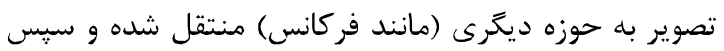

$$
\begin{aligned}
& \text { اطلاعات در ضرايب تبديل جاسازى مىشود. }
\end{aligned}
$$

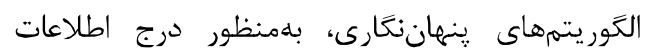

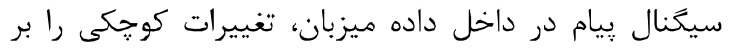

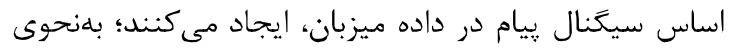

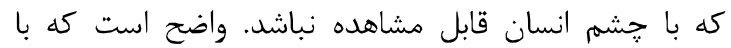

$$
\begin{aligned}
& \text { افزايش دادههاى جاسازىشده در يكى تصوير، احتمال } \\
& \text { مشكوكشدن تحليلگر به وجود ييام ينهان در تصوير مورد }
\end{aligned}
$$

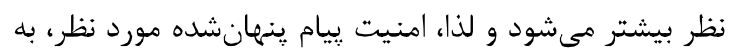

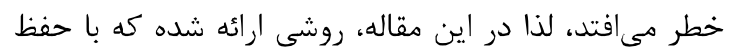

$$
\begin{aligned}
& \text { كيفيت تصوير ينهاننغارىشده، امنيت ارتقا يابد [1]. }
\end{aligned}
$$

\section{r- مرورى بر بز بروهش هاى مرتبط}

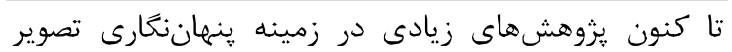

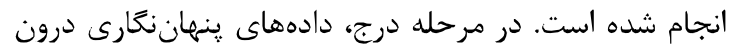

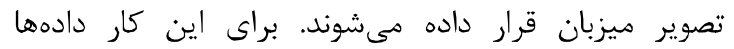
مىتوانند در حوزه مكان يا در حوزه تبديل در تصوير قرار داده شوند. قراردادن داده در حوزه مكان يك روش ساده با هزينه محاسباتى بسيار كم ولى داراى مقاومت ناجيزى در برابر فشردهسازى تصوير است. در زمان استفاده از حوزه تبديل، ابتدا برروى تصوير ميزبان يك تبديل مانند تبديل

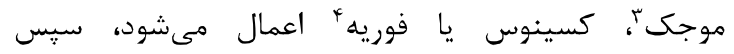
زيرمجموعهاى از ضرايب تبديل انتخاب و بر اساس دادههاى

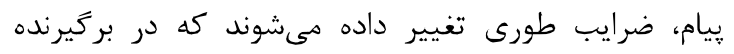

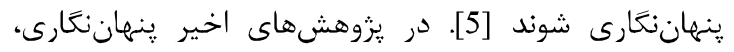
تأكيد بر استفاده از تبديل موجك است؛ بعد از اين مرحله،

${ }^{3}$ Wavelet

${ }^{4}$ Fourier transform

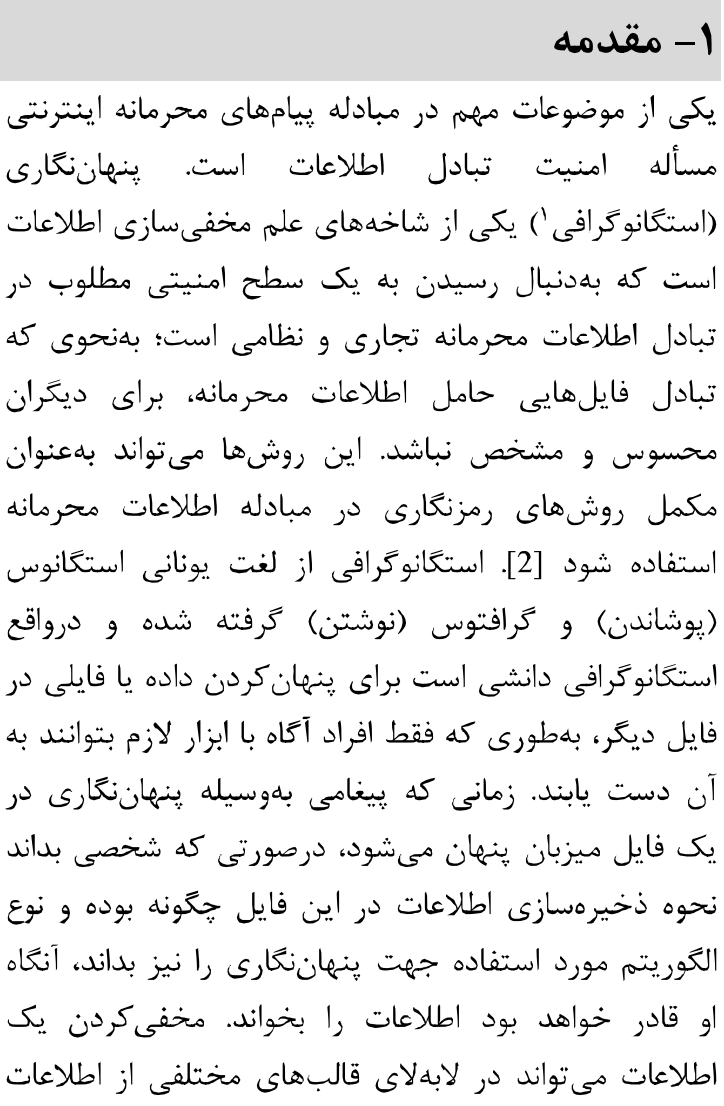

مانند متن، صوت، تصوير و شبكه باشد [3].

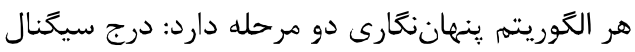

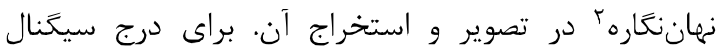
نهان نغاره مىتوان از حوزه مكان يا حوزه تبديل استفاده كرد.

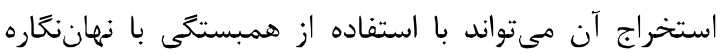

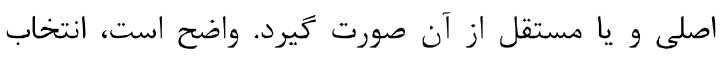
روش درج و نحوه استخراج نهاننگاره به همم وابستهاند [4]. در روشهاى حوزه مكان اطلاعات بهطورمستقيم در شدت

${ }^{1}$ Steganography

${ }^{2}$ Watermark 
در هيزوهش [9] روش LSB2 بهعنوان روش پِيه در

نظر گرفته شده و جهت بهبود كيفيت و امنيت تصوير، تصوير

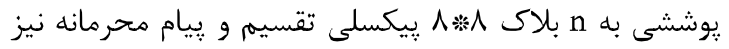

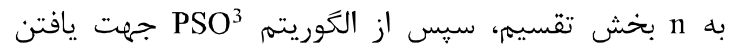

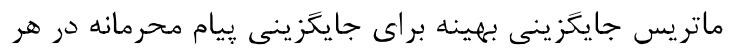

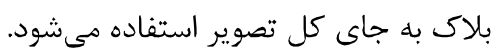
در مطالعه [10] تركيب دو الكوريتم فرابتكارى PSO

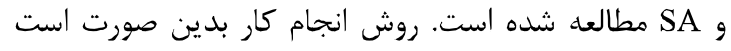
كه در ابتدا الكوريتم PSO به دادهها اعمال شده و بهترين نتيجه بهدستآمده از اين الكوريتهم بهعنوان پاسخ اوليه در

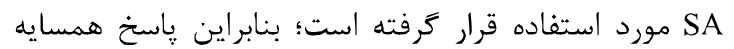
توليدشده در SA بر مبناى ياسخ بلدستآمده در الكوريتم

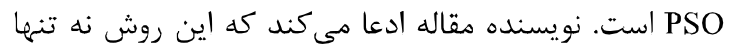
موجب بهبود كيفيت تصاوير مىشود، بلكه امنيت اطلاعات كدشده را نيز بdخوبى تضمين مى كند.

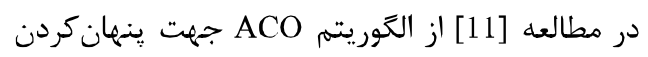
دادهها در يیيكسلهاى لبهاى تصوير استفاده شده است. در يزوهشى ديخر [12] ابتدا تصاوير به بلوكهايى تقسيمم، سيس

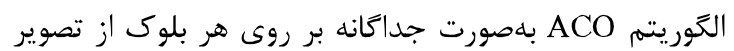

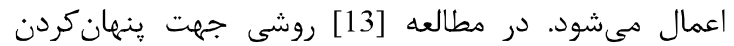
دادهها در حوزه فركانس با استفاده از الگوريتم زنتيك (GA) ارائهشده و يروهش

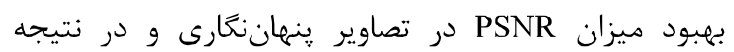

$$
\text { بهبود كيفيت تصاوير شود. }
$$

(جدول - (): فهرست الكَور يتمهاى فر البتكارى بهاك كار رفته در ينهان نتكارى تصاوير

(Table-1): The list of algorithms used in the image

\begin{tabular}{|c|c|c|}
\hline \multicolumn{3}{|c|}{ steganography } \\
\hline مرجع ( مرجع & مخفف & ن ام الكور يتم \\
\hline [14] & $\mathrm{ACO}^{4}$ & بهيندسازى كلونى مورجه \\
\hline$[16],[15]$ & $\mathrm{BA}^{5}$ & الكوريتم زنبور عسل \\
\hline [17] & $\mathrm{CS}^{6}$ & الكَوريتم جستجوى فاخته \\
\hline $\begin{array}{c}{[19],[18]} \\
{[20]}\end{array}$ & $\mathrm{GA}^{7}$ & الكوريتهم زنتيك \\
\hline $\begin{array}{c}\text {, [22], [21] } \\
{[30]}\end{array}$ & $\mathrm{PSO}^{8}$ & الكوريتم بعينهسازى حركت ذرات \\
\hline$[23]$ & $\mathrm{SA}^{9}$ & تبريد شبيهسازى شده \\
\hline [24] & $\mathrm{FA}^{10}$ & الكوريتم بجينهسازى كرم شبتاب \\
\hline
\end{tabular}

${ }^{2}$ least significant bit

${ }^{3}$ Particle swarm optimization

${ }^{4} \Lambda$ nt Colony Optimization

${ }^{5}$ Bee Algorithm

${ }^{6}$ Cuckoo Scarch Algorithm

${ }^{7}$ Genetic Algorithm

${ }^{8}$ Particle Swarm Optimization

${ }^{9}$ Simulatcd Anncaling

${ }^{10}$ Firefly Algorithm
تصوير ينهان نغارىشده آماده انتشار خواهد بود. مراحل بعدى

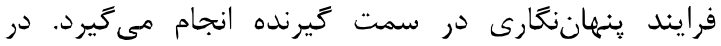
كيرنده، از تصوير ينهان نغارىشده كه تحت تأثير حملات و تغييرات عمدى و غيرعمدى در زمان انتشار قرار كرفته است،

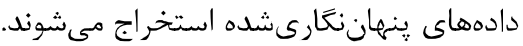

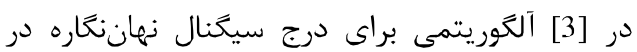
يك تصويرخاكسترى، به روش طيف كسترده در حوزه تبديل

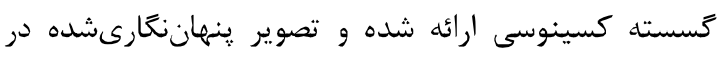

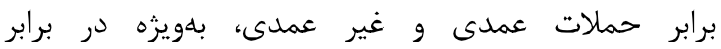
فشردهسازى JPEG مقاوم شده است. در يثوهشى ديخر [6] تبديل گسسته كسينوسى بر روى بلوكهاى ^×^ تصوير

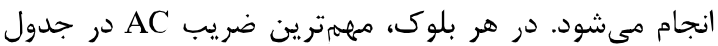
براى درج هر ضريبى از سيخنال طيف كَترده نهاننخاره، انتخاب شده است. ترك

كارهايى نيز با استفاده از تبديل موجك انجام شده است كه در اين روشها ابتدا تبديل موجك تصوير بلهدست مى آيد و يس از بهدستآوردن ضرايب موجك، اطلاعات موردنظر در آن جاسازى شده است. بهعنوان مثال در يكى از

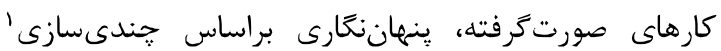
ضرايب فركانس وايين تبديل موجك بنا شده و از الكوهاى

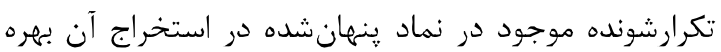

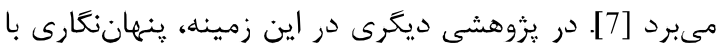

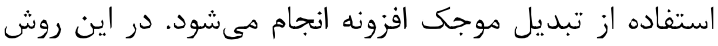
سيخنال نهاننكاره در بخش فركانس ڤايين تصوير ميزبان ينهان مىشود. اين روش داراى مقاومت بالايى است و نهاننخاره را مى توان با خطاى كمى از تصوير استخراج كرد. در ابتدا از ضرايب تبديل موجك مختلط تصوير براى محاسبه يك ماسك ديدارى استفاده شده و سيس با استفاده از اين ماسك نهاننگارهاى كه به خصوصيات تصوير وابسته باشد، توليد مىشود. براى هينهانسازى نهاننگاره نيز از ضرايب

تبديل موجك مختلط سطح سوم استفاده شده است [5].

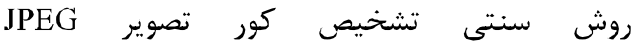
ينهان

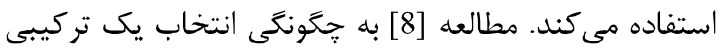
از ويزگى هاى برتر براى دستيابى به تشخيص بهرتر برداخته

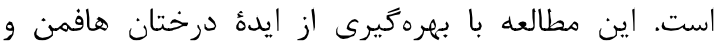

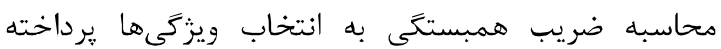
است. بهطورى كه در هر بار به تركيب دو ويزگى كه كمترين ضريب همبستخى را دارند، مىيردازد.

${ }^{1}$ quantization 
ץ-ץ- الكوريته بهينهسازى كلونى مورجه (ACO)

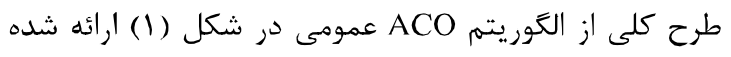
است. مراحل زير نحوه اجراى اين الكَوريتم فرابتكارى رادي ادر

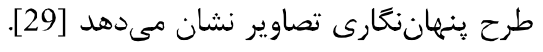

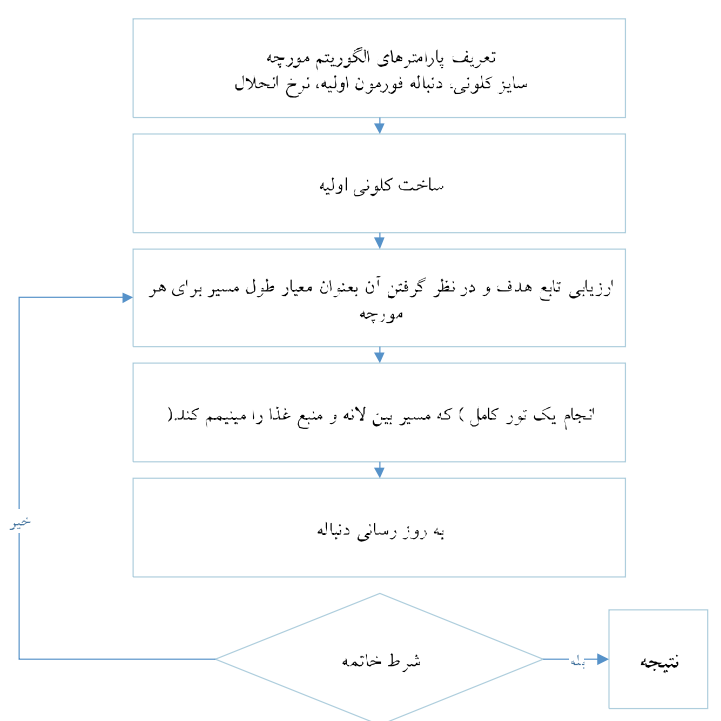

(شكل - (1): شماى الكوريتم كلونى مورجه

(Figure-1): An Ant Colony Algorithm Schema

مرحله ا: تعيين اندازه كلونى، دنباله فرمون اوليه، نرخ

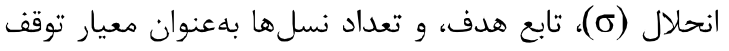
الكوريتم.

مرحله r: توليد تصادفى يك جمعيت اوليه از مورجهها، كه

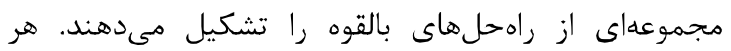
مورجه بهصورت فرمول زير نحوه توليد جمعيت اوليه را نشان مى دهدي. $f_{\text {pheromone }}\left(x_{i}\right)=e^{\frac{\left(x_{i}-x_{i}^{*}\right)^{2}}{2 \sigma_{i}^{2}}}$

كه در آن است كه دأ برابر باi امين مختصات بهترين

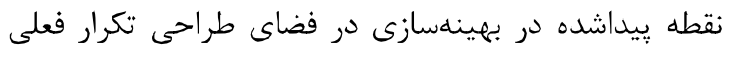

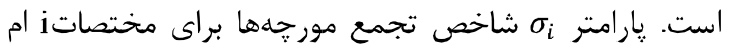

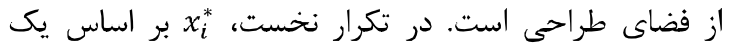

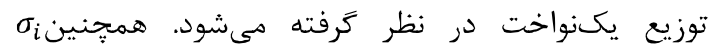
دستكم سه برابر بزرگتر از طول فاصله جستجو انتخاب مى شود. مرحله سا: براى هر مورو خه

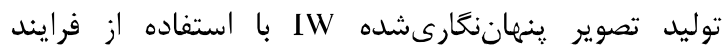
تعبيهسازى انجام شود.
استفاده از الكَوريتمهاى بهينهسازى مبتنى بر الكَوريتمهاى فرا ابتكارى و الكَوريتمهاى مبتنى بر محاسبات

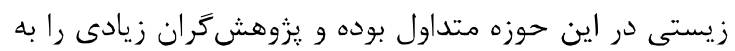

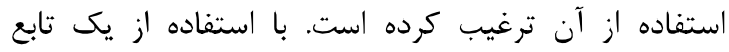

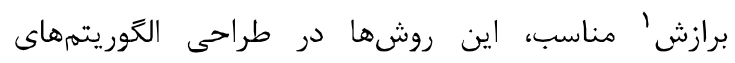

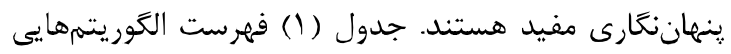
است كه در اين حوزه بهكار رفتهاند.

r- ب- روش استفادهشده در اين هزوهش

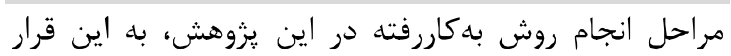

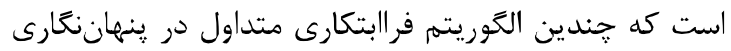
تصاوير بر اساس مراجع يادشده در بخش قبن إنبل، مورد استفاده

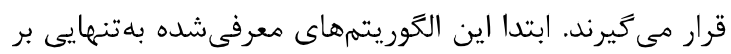

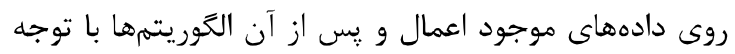

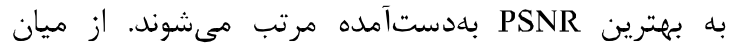
الكَوريتمهاى اعمالشده، سه الكَريتمى كه نتيجه بهنئ

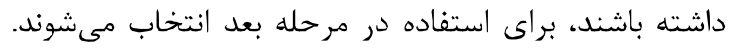
شش حالت مختلف از تركيب اين سه الكوريته بهطور مجزا بررسى و نتيجه نهايى ثبت مىشود و تركيبى كه بهترين

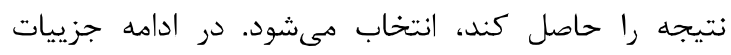
مربوط به تركيب الكَوريتهها را شرح خواهيم داد.

ا-r- تابع برازش بهكار رفته

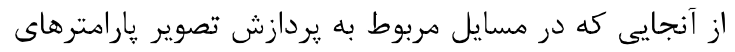

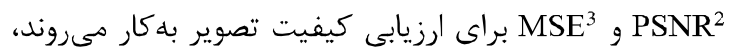

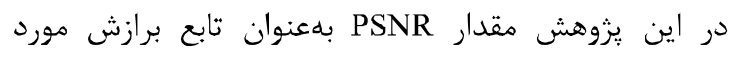

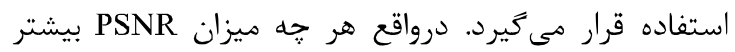

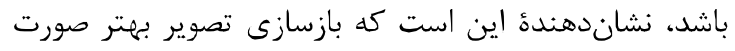
كرفته و كيفيت تصوير بالاتر است و در نتيجه امنيت ينهاننغارى بهتر حفظ خواهد شد. $P S N R=10 * \log _{10}\left(255^{2} / M S E\right)$

$M S E=\frac{1}{W * H} \sum_{i=1}^{W} \sum_{j=1}^{H}\left(s_{i j}-c_{i j}\right)^{2}$

ij $c_{i j} c_{i j}$

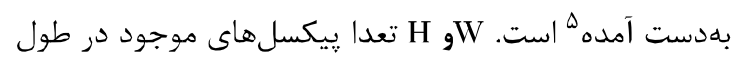
و عرض تصوير اوليه است.

1 Fitness function

${ }^{2}$ peak signal to noise rate

${ }^{3}$ mean square error

${ }^{4}$ Cover Image

${ }^{5}$ stego-image 
كه در آن rand(0.1) يك عدد تصادفى با توزيع نرمال بين صفر و يك است.

$X_{i j}=x_{m i n . j}+\operatorname{rand}(0.1) *\left(x_{\max . j}-x_{\min .1}\right)$

در الكوريته ABC، هر جرخه از جستجو از منابع غذايى

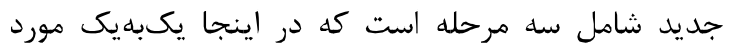

$$
\text { بحث قرار مى ندهيم: }
$$

زنبور عسل شاغل: زنبور به كار توليد يك راه حلاه حل

جديد بسته به اطلاعات محلى يرداخته و مقايسه تناسب راهن راه

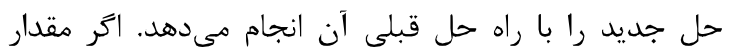

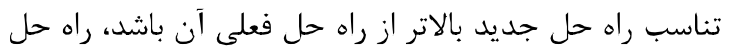

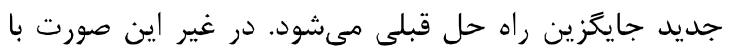

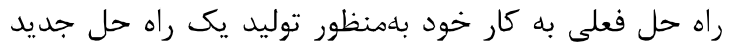

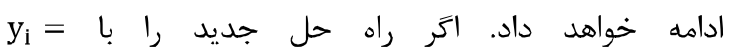

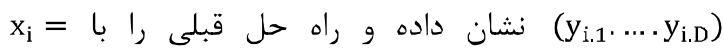
نشان دهيم، الكوريتهم بهينهسازى مورجه بدين صورت عمل مى كند: (x)

$$
\mathrm{y}_{\mathrm{i} . \mathrm{j}}=\mathrm{x}_{\mathrm{i} . \mathrm{j}}+\varphi_{\mathrm{i} . \mathrm{j}} *\left(\mathrm{x}_{\mathrm{i} . \mathrm{j}}-\mathrm{x}_{\mathrm{k} . \mathrm{j}}\right)
$$

كه در آن

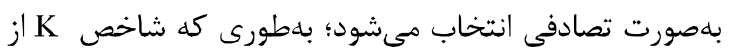

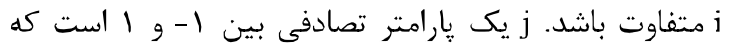

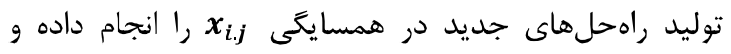

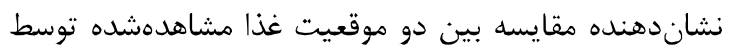
يك زنبور عسل را نشان مى دهند.

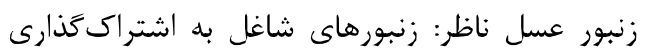

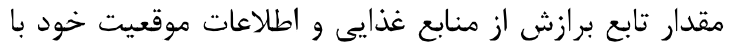

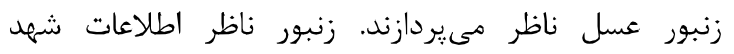

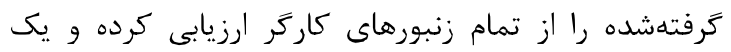

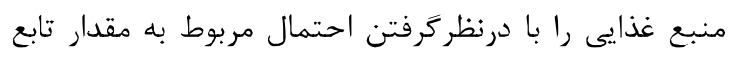
برازش آن انتخاب مي كند. بدين ترتيب مقدار شهد از ماده غذايى افزايش مى انيابد

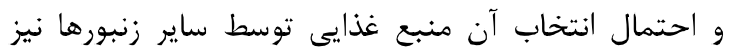

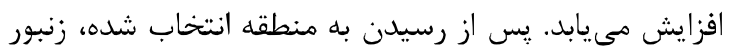

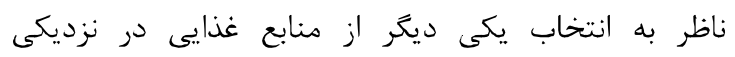

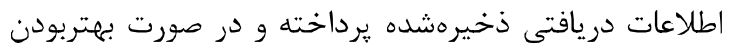

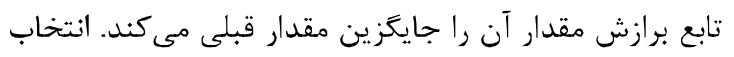

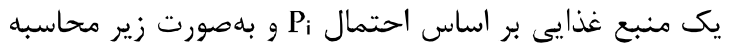

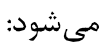
$P_{i}=\frac{f i t_{i}}{\sum_{i=1}^{S N} f i t_{i}}$
•محاسبه همبستخى نرمال بين تصوير اصلى و تصوير ينهان ينًارى شده: NC(I,IW)

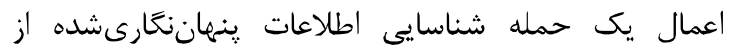

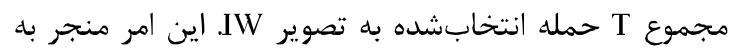
تصاوير ينهاننغارى حمله شده متفاوت براى هر تصوير

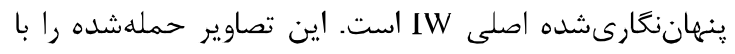
مى شیناسيهم. $\left\{I^{\prime}{ }_{W}\right\}$ استخراج دادهاى ينهانغارىشده از تصاوير مورد حمله واقع شده

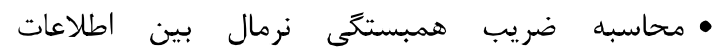

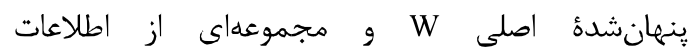
استخراجشده.

•ساخت بردار ارزشهاى هدف، F (X) كه بلهورت زير تعريف مىشود:

$F(X)=\left(\frac{1}{N C\left(I . I_{W}\right)} \cdot \frac{1}{N C\left(W \cdot W^{\prime}\right)} \cdot \frac{1}{N C\left(I . W^{\prime} 1_{1}\right)} \cdot \cdots \cdot \frac{1}{N C\left(I . W_{T}^{\prime}\right)}\right)$

$$
\text { •ارزيابى بردار ارزشهاى هدف و شناسايى بهترين مسير }
$$

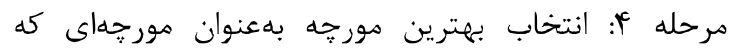

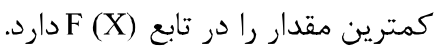

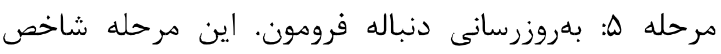
تجمع براى oi بعد أl برابر است با:

$\sigma_{i}=\sqrt{\frac{1}{m}} \sum_{i=1}^{m} y_{i}-y^{\prime}$

كه در آن y برابر با أمين ستون از ماتريس كلونى C است.

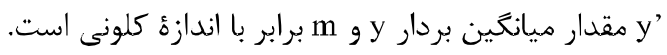

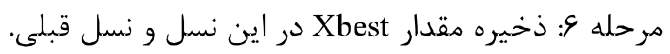

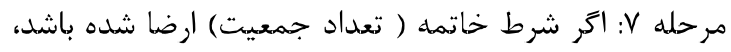

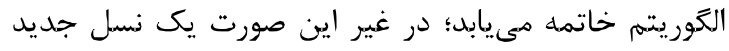
ايجاد شده و به مرحله r باز مى كردد.

\section{ץ-r- الكوريتم بهينهسازى زنبور عسل در ينهان (ABC $\left.{ }^{1}\right)$}

در الكوريتم بجينهسازى زنبور، درحالى كه زنبورهاى ناظر و وان

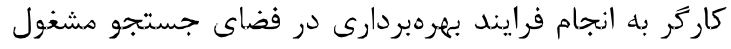

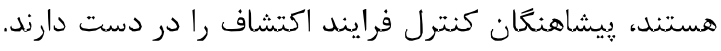
در مرحله نخست، مجموعهاى از منابع غذايى بهطور تصادفى

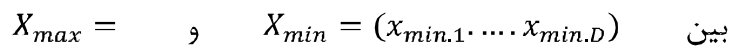
(x) بهورت معادله زير حساب هىشود؛

\footnotetext{
${ }^{1}$ Artificial bee colony
} 


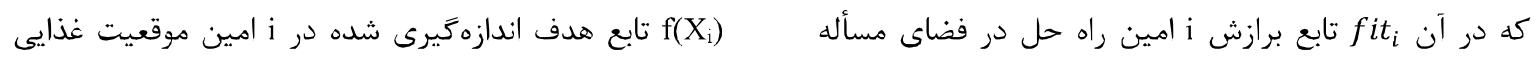

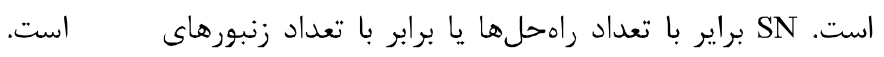
$f i t_{i}=\left\{\begin{array}{cc}\frac{1}{f\left(X_{i}\right)} \quad \text { if } f\left(X_{i}\right) \geq 0 \\ 1+a b s\left(f\left(X_{i}\right)\right) \quad \text { elsewhere }\end{array}\right.$

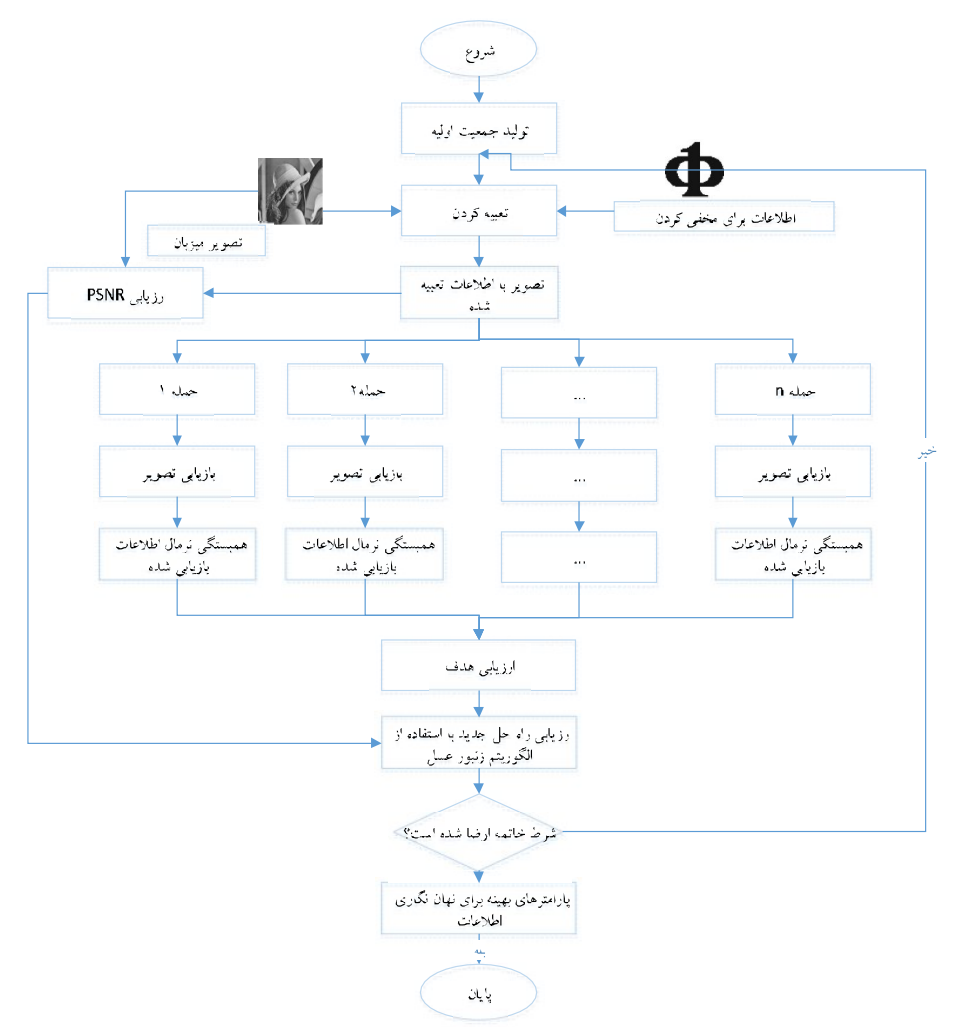

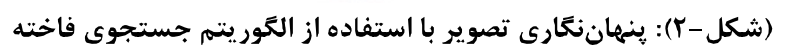
(Figure-2): Image steganography using the Cuckoo search algorithm

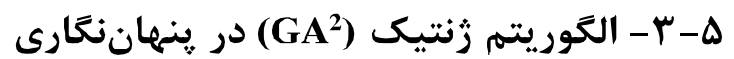

$$
\text { تصاوير }
$$

براى استفاده از الكَوريتم رُنتيك لازم است تا ابتدا ماتريس

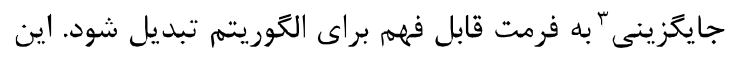

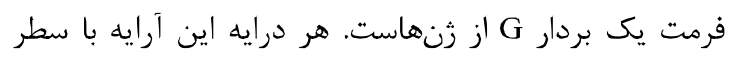

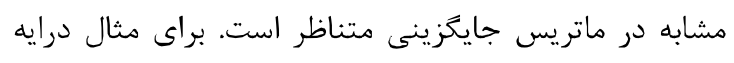

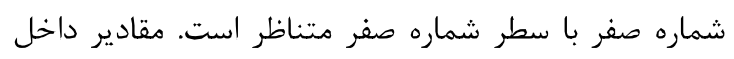

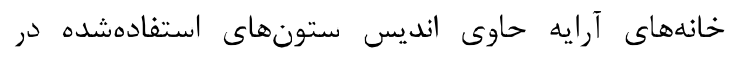

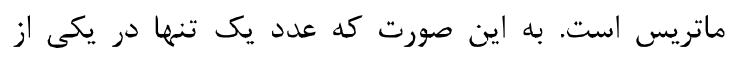

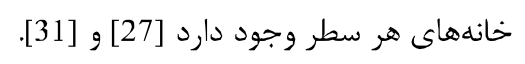

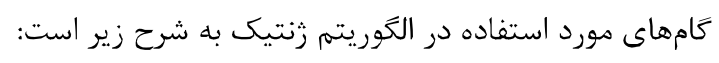

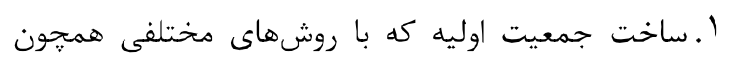

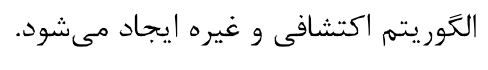

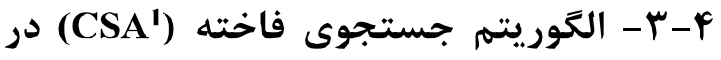 ينهان ينَارى تصاوير}

مقداردهى جمعيت اوليه توسط مولد عدد تصادفى بين يكى و

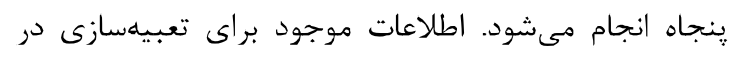

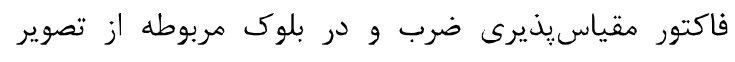

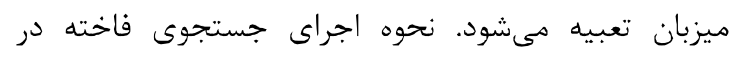

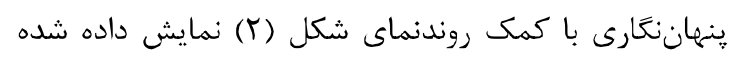

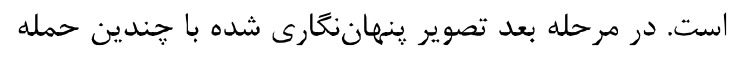

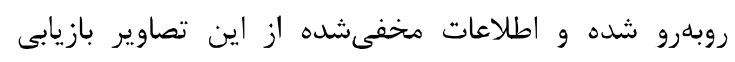

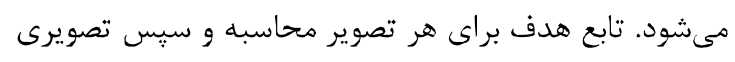

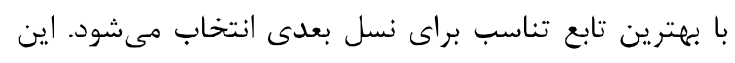

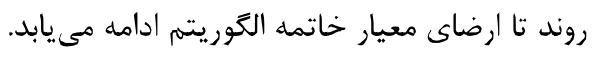

${ }^{1}$ Cuckoo search Algorithm 
با استفاده از الكوريتم SA يك جواب همسايه Sُ براى مسأله توليد مىشود. مقدار دلتا و PSNR براى اين جواب محاسبه

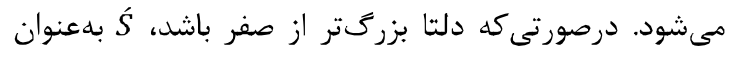
جواب اويله در نظر كرفته مىشود؛ در غير اين صورت كُ كان بان احتمال e-

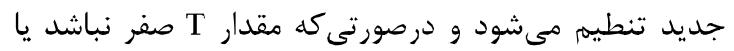

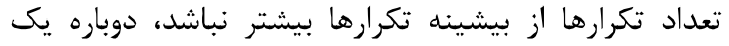

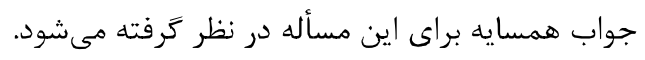

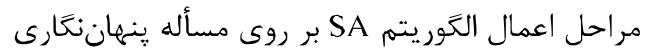

$$
\text { تصاوير بهصورت زير خواهد بود: }
$$

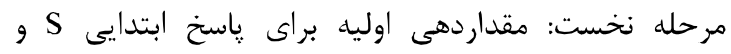
همجنين بهترين راه حل يافت (bestsol) براى SA الكوريته انجام و همجنين يك مقدار اوليه براى دماى T در نظر كرفته

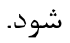

PSNR و مرحله دوم: يك جواب همسايه 'PS

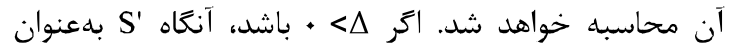

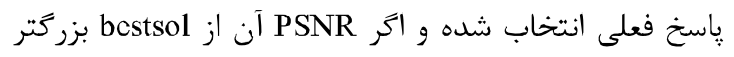

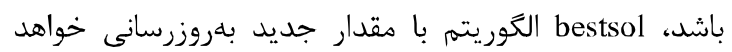
شد. در غير اين صورت الكَوريتم به مرحله بعدى حركت مى كند. مرحله سوم: يك عدد تصادفى با توزيع يكنواخت بين [ـ، 1]

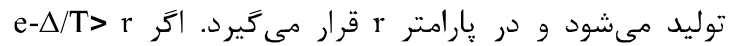
باشد، ' S بهعنوان קاسخ فعلى معرفى خواهد شد.

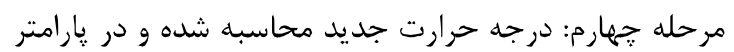
T مقداردهى مىشود. T مرحله هنجم: اكر T \# • • و يا تكرار تعداد تكرار كمتر از بيشينه

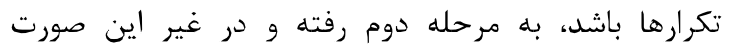

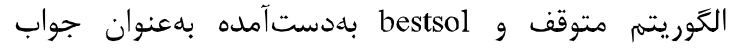
معرفى خواهد شد.

\section{V- V- الكوريتم بهينهسازى حركت ذرات در :}

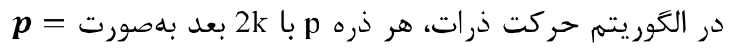

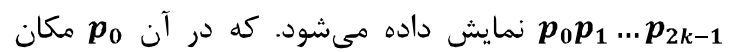
عدد يك در سطر صفرم ماتريس جايكزينى، يك در سطر نخست ماتريس جايكزينى و ... است. [28] يك ماتريس جايكزينى متناسب با ذره p در شكل (َ) بهصورت نمونه مشاهده مىشود. هر ذره با يكى ماتريس جانشينى

${ }^{5}$ Particle swarm optimization
Y. انتخاب و تركيب نمونههاى (آرايه) اوليه براى توليد نمونه

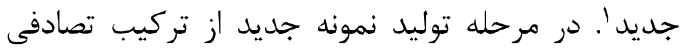
دو يدر براى توليد فرزند جديد استفاده مىشود.

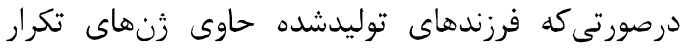

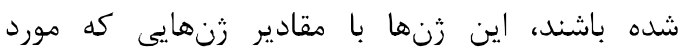
استفاتده قرار نكرفتهاند، جايغزين مىشوندا كاندان كل مرحله توليد نمونه جديد در يك تكرار ده تايى با تركيب ده زوج

$$
\text { تصادفى انتخاب شده انجام مىشود. }
$$

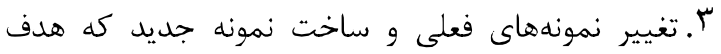

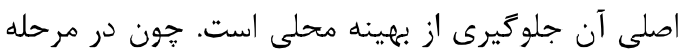
توليد نمونه جديد ممكن است از نمونه إنهائه محلى مشابه براى تركيب استفاده شده باشد.

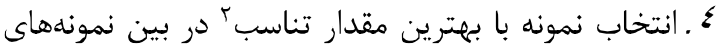
توليدشده در اين نسل براى توليد نسل بعدى نمونهها تا

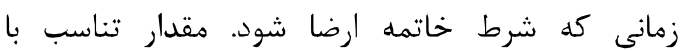
اندازهيرى معيارهايى از قبيل PSNR انجام مىشود. براى جهبود كيفيت تصوير توليدشده از روش بهربودئ ييونددهى مجدد مسير استفاده شده است. روش كار بال

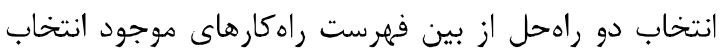

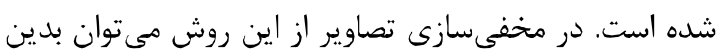
صورت استفاده كرد كه بِ از هر اجراى الكوريتم زُنتيك كه تعداد ده تا از بهترين آرايهها انتخاب مىشوند و و بهطور

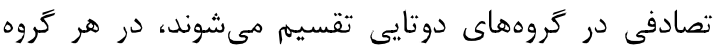

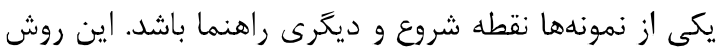

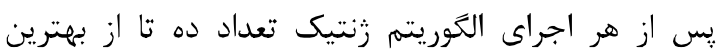
آرايهها را انتخاب كرده و بهطور تصادفى در كروههاى دوتايى لني تقسيم مىشوند، در هر گروه يكى از نمونهها نقطه شروع و ديخرى راهنما باشد.

\section{צ-r- الكوريتم تبريد شبيهسازىشده (SA) در ينهان نغارى تصاوير}

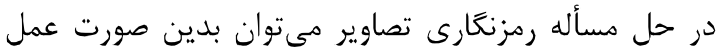
كرد كه n جمعيت مطلوب نهايى رادر اين الكَوريته بهعنوان

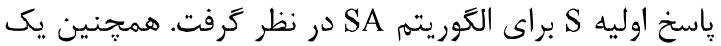
مقدار اوليه براى دما در نظر كرفته خواهد شد. در مرحله بعد برد

\footnotetext{
${ }^{1}$ Crossover

${ }^{2}$ fitness

${ }^{3}$ PATH RELINKING REFINEMENT

${ }^{4}$ Simulated Annealing
} 
• تعبيهسازى متن در تصوير انجام شود.

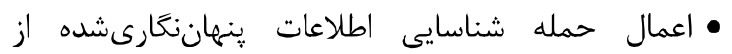
مجموع T حمله انتخابشده به تصوير ينهان نكارىشده. اين امر منجر به T تصاوير ينهاننغارى حملهشده متفاوت

$$
\text { براى هر تصوير هنهاننارىشده اصلى مىشود. }
$$

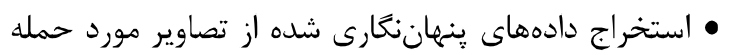

واقعشده با استفاده از فرايند استخراج.

• محاسبه تابع برازش PSNR براى هر تصوير و مقداردهى

$$
\text { به تابع برازش مربوط به هر كرم شبتاب براب }
$$

مرحله سوم: بلروزرسانى مكان هر كرم شبتاب با استفاده از تابع برازش بهدستآمده.

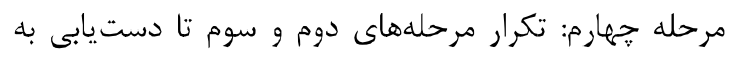
بيشينه تعداد حلقهها.

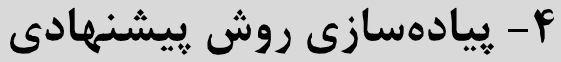

در اين يزوهش از تصاوير رنكى ليَ JPEG استاندارد در حوزه يردازش تصوير كه داراى طيف رنخى غنى (هر سه يايه ( RGB استاندارد به كار رفته در مقالههاى ينهاننگارى از جمله منابع

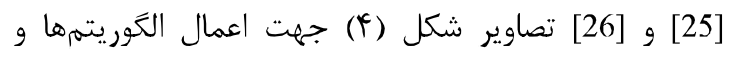
ارزيابى انتخاب شدهاند.

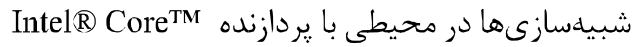

i7 CPU @2.3 GHz

شده و سيستم عامل مورد استفاده 7 Ultimate 64Bit

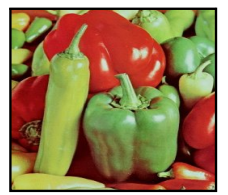

ج) فلفل

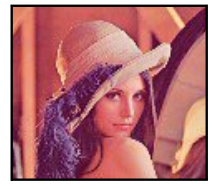

ب) لنا

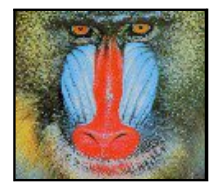

الف) بابون
(شكل -F): تصاوير استفاده شده در اين يثرهش

(Figure-4): Images used in this research

1-F- اعمال الكوريتههاى فرابتكارى بلهصورت

$$
\text { جداتانه }
$$

در اين بخش ڤارامترها و نتايج اعمال الخوريتهماى فرابتكارى بهصورت جداگانه شرح داده شده است.
همسان است؛ بنابراين، هر ذره با بهترين مقدار تابع تناسب به ماتريس جانشينى كه مىتواند تصوير ينهان نغارى توليد كند، برابر است. هر ذره p بايد يكى بردار از اعداد صحيح در محدوده صفر تا مK-1 باشد. $\left[\begin{array}{llll}1 & 0 & 0 & 0 \\ 0 & 1 & 0 & 0 \\ 0 & 0 & 0 & 1 \\ 0 & 0 & 1 & 0\end{array}\right]$ $\left\{\begin{array}{llll}0 & 1 & 3 & 2\end{array}\right\}$

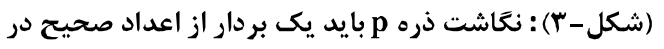
محدوده • تا 2K-1 باشد

(Figure-3): The particle mapping p must be a vector of integers in the range 0 to $2 \mathrm{~K}-1$

شرح نحوه جستجو يك ماتريس جايخزينى از طريق الخوريتم PSO بهصورت زير خواهد بود: مرحله ا: مقدار دهى اوليه. بهطور تصادفى K ذره اوليه توليد

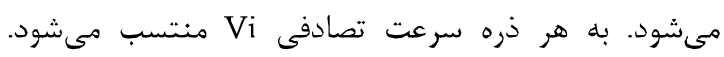
محاسبه PSNR براى هر ذره انجام شده وgbest را با داب مكان

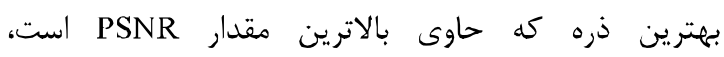

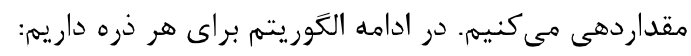

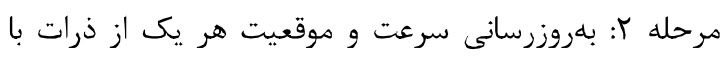

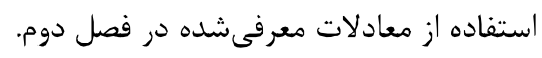

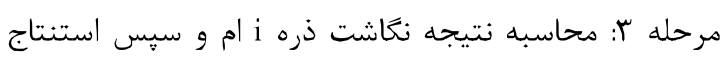
مربوطه و بررسى اينكه اين PSNR به gbest بيشتر است يا خير. در صورت بزرت تربودن، مقدار

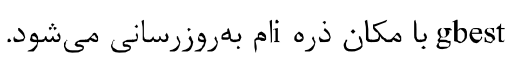

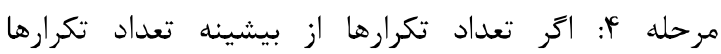
كوجىتر است، به مرحله دوم رفته و در غير اينص

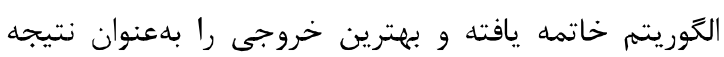
نهايى معرفى مي كند.

1-r-1- الكوريتم كرم شبتاب (Firefly) در ينهان إنغارى تصاوير

مراحل اعمال الكوريتهم كرم شبتاب در مسأله ينهاننغارى

$$
\text { تصاوير به قرار زير است: }
$$

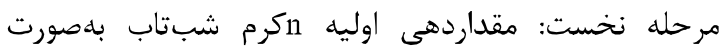
تصادفى كه در آن هر كرم شبتاب يكى رديف از ماتريس

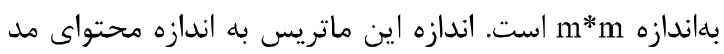
نظر براى ينهان نغارى است.

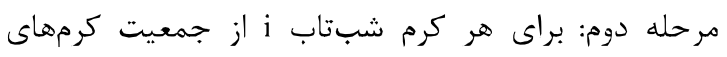
شبتاب داريه: - مئه 


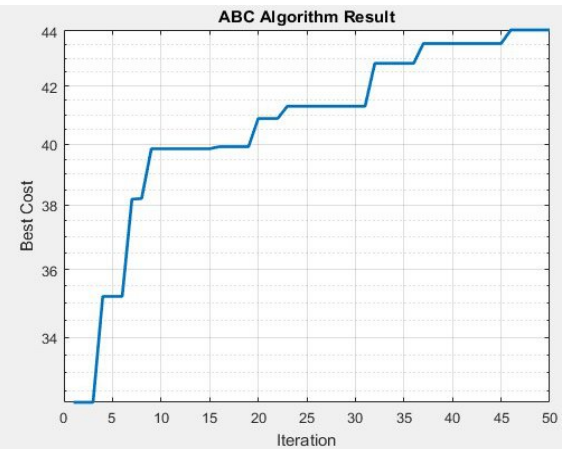

(شكل - ()): نمودار افزايش مقدار PSNR در تكرارهاى مختلف

اجراى الكوريتم بهينهسازى زنبور عسل در تصوير لنا

(Figure-6): Diagram of PSNR increment in different repetitions of the Bee algorithm in the Lena image

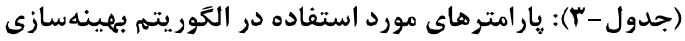

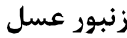

(Table-3): Parameters used in the bee optimization algorithm

\begin{tabular}{|c|c|c|}
\hline مقدار & توصيف & هارامتر \\
\hline 20 & تعداد زنبورهاى ناظر & $\mathrm{n}$ \\
\hline 10 & تعداد مكانهاى ازتخاب هاى شدهد ازيد شده & $\mathrm{m}$ \\
\hline 5 & تعداد بهتر ين مكان ها از مكان هاى & $\mathrm{e}$ \\
\hline 6 & تعداد زنبور هاى تازه نفس براى & nep \\
\hline 4 & تعداد زنبورهاى استخدام شده براى & $\mathrm{t}$ \\
\hline 50 & تعد اد تكرار & loop \\
\hline
\end{tabular}

ץ-1-1 - اعمال الكوريته فر ا ابتكارى جستجوى فاخته شكل (V) نحوه تغيير مقدار PSNR در اعمال الكوريتم فرابتكارى جستجوى فاخته را بر روى تصوير لنا نشان

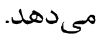

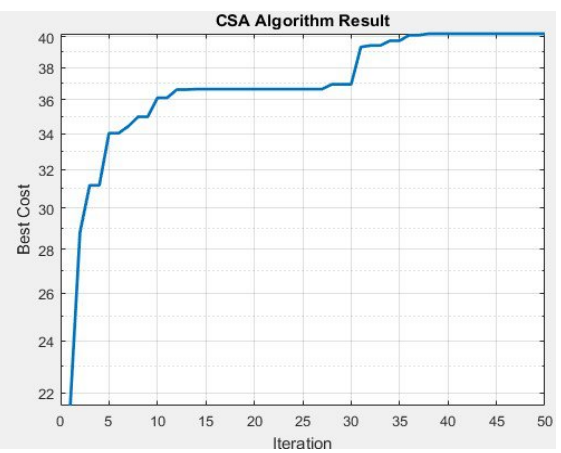

(شكل - ( ) نمودار افزايش PSNR در تكرارهاى مختلف اجراى

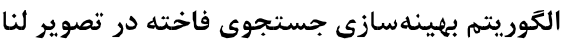

(Figure-7): Diagram of PSNR increment in different repetitions of the Cuckoo search optimization algorithm in the Lena image

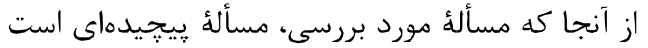

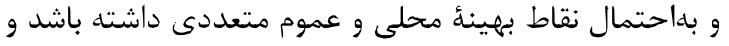

|-1-1 - | اعمال الكوريتم بهينهسازى كلونى مورجه

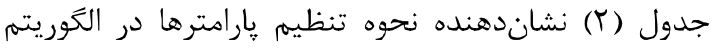
بهينهسازى كلونى مورجه است كه مورد استفاده قرار كرفته

(جدول - (T): يارامترهاى مورد استفاده در الكوريتم بجينهسازى كلونى مورجه إنه

(Table-2): Parameters used in ant colony optimization algorithm

\begin{tabular}{|c|c|c|}
\hline مقدار & توصيف & 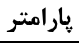 \\
\hline 6 & تعداد كل مورجهها & $\mathrm{m}$ \\
\hline 0.5 & مقدار اوليه فرومون & ז0 \\
\hline 2 & غلظت فرومون & $\tau$ \\
\hline 1 & وزن غلظت فرومون & $\alpha$ \\
\hline 1 & ارزش تجربه & $\beta$ \\
\hline 0.7 & ارزش تجربه & $\eta$ \\
\hline 21 & تعداد سفرهاى باز كشت & $\mathrm{T}$ \\
\hline 0.7 & يارامتر از تبخير فرومون & $\rho$ \\
\hline 0.2 & يارارامتر عدد تصادفى & QO \\
\hline 50 & تعداد تكرار & loop \\
\hline
\end{tabular}

در شكل (ه) نتايج حاصل از اعمال روش ACO بر

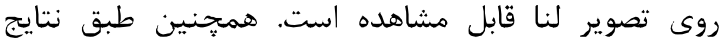
بهدستآمده در جدول (9)، در مقايسه روش ACS و ACO

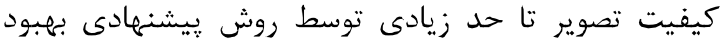

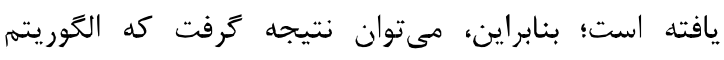
ACO

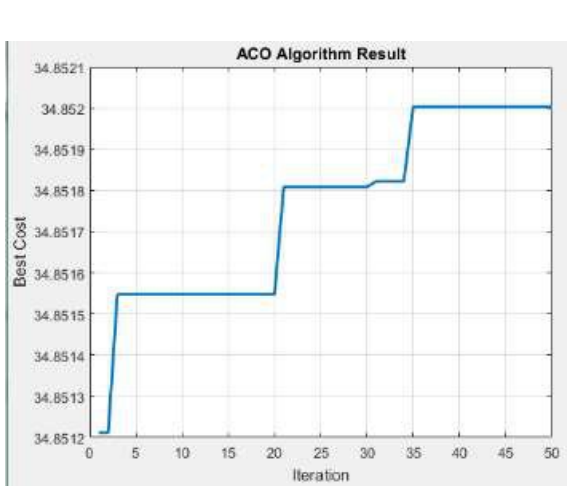

(شكل -ه) : نمودار افزايش PSNR در تكرارهاى مختلف اجراى

$$
\text { الكوريتم ACO در تصوير لنا }
$$

(Figure-5): Diagram of PSNR increment in different repetitions of the $\mathrm{ACO}$ algorithm in the Lena image

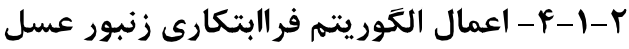
شكل (ع) نحوه تغيير مقدار PSNR را در اعمال التوريتهم

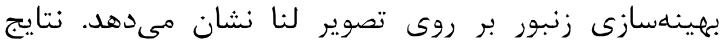

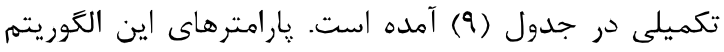
طبق جدول (r) ت تنظيم شدهاند. 


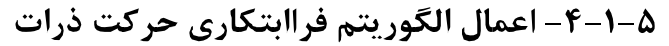
شكل (9) نحوه تغيير مقدار PSNR در اعمال الكوريته

فرابتكارى حركت ذرات را بر روى تصوير لنا نشان مى دهدهد.

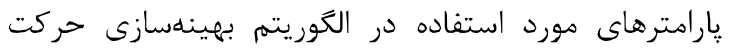
ذرات در جدول (9) نمايش داده شده است.

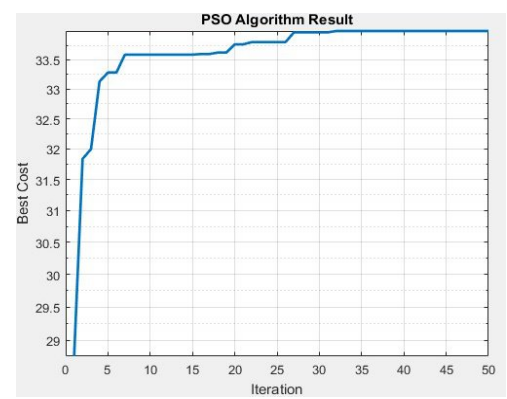

(شكل -9): نمودار افزايش مقدار PSNR در تكرارهاى مختلف

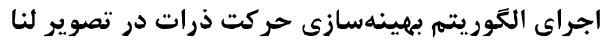

(Figure-9): Diagram of PSNR increment in different repetitions of the Particle Swarm optimization algorithm in the Lena image

(جدول-9): يار امترهاى مورد استفاده در الكوريتهم بهينهسازى

$$
\text { حركت ذرات }
$$

(Table-6): Parameters used in the Particle Swarm

\begin{tabular}{|c|c|c|}
\hline \multicolumn{3}{|c|}{ Optimization algorithm } \\
\hline مقدار & توصيف & 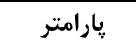 \\
\hline 1 & تعداد يارامترهاى تصميمكيرى & nVar \\
\hline 1000 & ماكزيمم تعداد حلقهها & MaxIt \\
\hline 1 & وزن اوليه & $\mathrm{w}$ \\
\hline 0.99 & ضريب تغيير وزن & wdamp \\
\hline 1.5 & نرخ ياديرى شخصى & c1 \\
\hline 2 & نرخ يادَّيرى عمومى & c2 \\
\hline$[-4,4]$ & سرعت كمينه و بيشينه & {$\left[\mathrm{V}_{\min }, \mathrm{V}_{\max }\right]$} \\
\hline
\end{tabular}

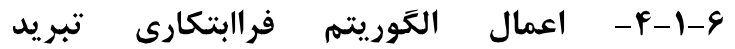

$$
\text { شبيهسازى شده }
$$

شكل (•) نحوه تغيير مقدار PSNR در اعمال الخوريتم فرابتكارى تبريد شبيهسازىشده را بر روى تصوير لنا نشان

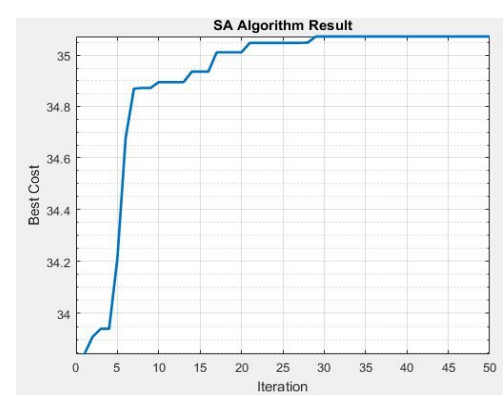

مى مدهد.

(شكل -•(1): نمودار افزايش PSNR در تكرارهاى مختلف اجراى

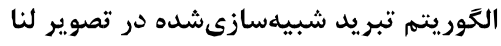

(Figure-10): Diagram of PS.NR increment in different repetitions of the Simulated Annealing algorithm in the Lena image
با توجه به مطالبى كه بيان شد، تعداد لانههاى الخَوريتهمهاى

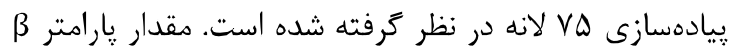

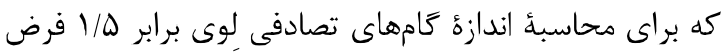
شده است. بيشينه تعداد تكرارها به ينجاه تكرار است. يارامترهاى اين التوريتم طبق جدول (أ) تنظيم شدهاند.

$$
\begin{aligned}
& \text { (جدول - F): هارامترهاى مورد استفاده در الكوريتم بهينهسازى } \\
& \text { جستجوى فاخته }
\end{aligned}
$$

\begin{tabular}{|c|c|c|}
\hline \multicolumn{3}{|c|}{ P } \\
\hline مقدار & توصيف & 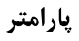 \\
\hline 1 & احتمال شناسايى تخهمهاى فاخته & $\mathrm{Pa}$ \\
\hline 0.25 & انتقال لانه به مكان جديد & a \\
\hline 75 & تعداد لانه ها & $\mathrm{n}$ \\
\hline 1.5 & اندازٔ كامهاى تصادفى & $\beta$ \\
\hline 50 & تعداد تكرار & loop \\
\hline
\end{tabular}

(Table-4): Parameters used in Cuckoo Search Optimization Algorithm

ش شكل (^) نحوه تغيير مقدار PSNR را در اعمال الكوريتهم فرابتكارى زنتيك را بر روى تصوير لنا نشان مى سدهد.

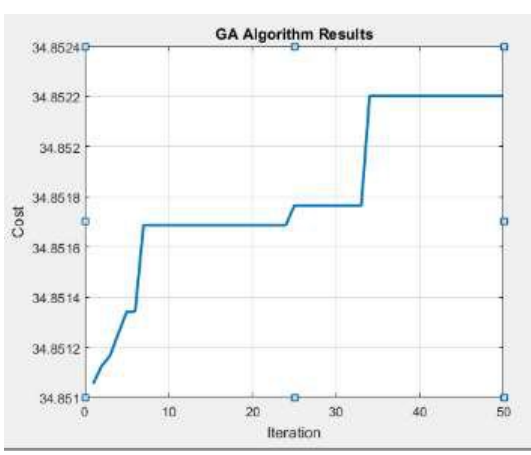

(شكل -1) : نمودار افزايش PSNR در تكرارهاى مختلف اجراى

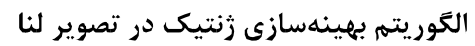

(Figure-8): Diagram of PSNR increment in different repetitions of the Genetic algorithm in the Lena image

يارامترهاى تنظيم شده در اجراى الكَوريتم مذكور، در جدول

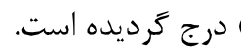

\begin{tabular}{|c|c|c|}
\hline مقدار & توصيف & إارامتر \\
\hline 100 & اندازه جمعيت & nPop \\
\hline 1000 & تعداد نسلها & n_gen \\
\hline (مقدار اوليه)10 & بردار وزن & $\lambda$ \\
\hline 0.8 & درصد تقاطع يا CrossOver & $r p$ \\
\hline 0.5 & درصد جهش يا Mutation & mu \\
\hline
\end{tabular}

(جدول -ه): يارامترهاى مورد استفاده در الكوريتم زنتيكى (Table-5): Parameters Used in the Genetic Algorithm 
بهينه بهدست مى آيد. يارامترهاى اين الكوريتم طبق جدول

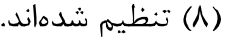

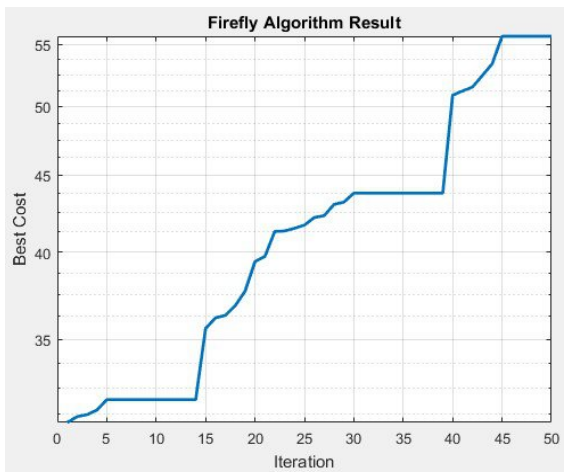

(شكل -1|): نمودار افزايش PSNR در تكرارهاى مختلف اجراى

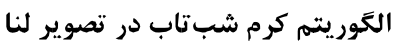

(Figure-11): Diagram of PSNR increment in different repetitions of the Firefly algorithm in the Lena image

\section{Y-F - شناسايیى الكوريتمهاى برتر}

در اين مرحله پِ إز بيادهسازى تمامى روشهاى ابتكارى

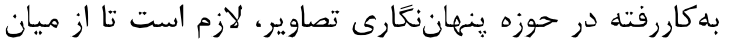

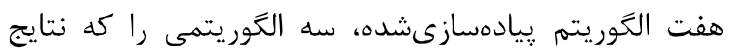
بهترى را بر روى دادهها نشان دادهاند، براى مرحله بعدى شبيهسازىها شناسايى كنيم. نتايج بهدستآمده از مقايسه

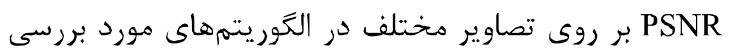
در اين مقاله در جدول (9) نمايش داده شده است.

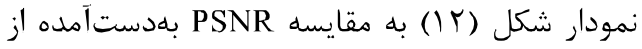

$$
\text { اجراى اين الكوريتمها مى يردازد. }
$$

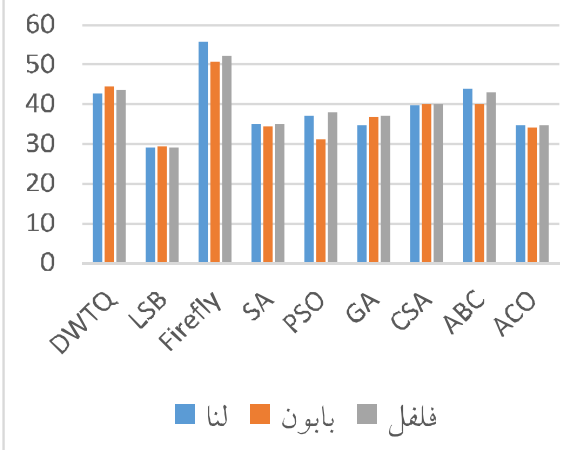

(شكل - I () مقايسه PSNR بهدست آمده از اعمال

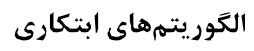

(Figure 12): Compar the PSNR obtained by applying the heuristic algorithms

همانطوركه در اين تصوير نشان داده شده است،

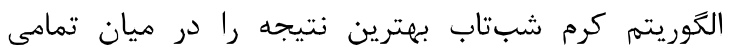

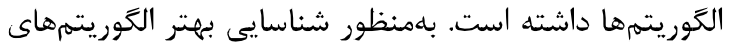

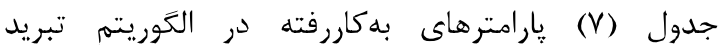

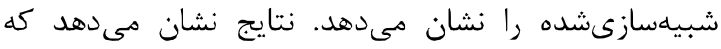
روش بيشنهادى مى تواند در بهببود كيفيت تصوير مؤثر باشد.

(جدول -V): يار امترهاى مورد استفاده در الكَوريته تبريد

شبيهسازى شوره

\begin{tabular}{|c|c|c|}
\hline مقدار & توصيف & 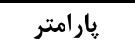 \\
\hline 100 & اندازه جمعيت & nPop \\
\hline 4 & تعداد يار امترهاى تصميمثيرى & nVar \\
\hline 50 & ماكزيمم تعداد حلقهها & MaxIt \\
\hline 2 & ماكزيمم تعداد حلقهها به ازاى هر دما & MIPTemp \\
\hline 2 & تعداد همسايههاى توليد شده در هر تكرار & nMove \\
\hline $\mathbb{Q}$ & دماى اوليه & T0 \\
\hline 0.9 & ضريب تغيير دما & RRT \\
\hline 100 & ت تعداد تكرار & loop \\
\hline
\end{tabular}

(Table-7): Parameters used in Simulated Annealing algorithm

P-1-V - - اعمال الغوريتم فرابتكارى كرم شب تاب

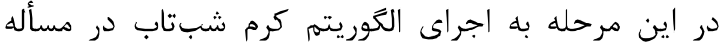

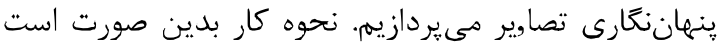

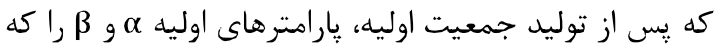
در جدول (^) به تفسير آمده است، مقداردهى مى كنيم.

(جدول-1): هار امترهاى مورد استفاده در التُريتهم كرم شب تاب

\begin{tabular}{|c|c|c|}
\hline مقدار & توصيف & يارامتر \\
\hline 100 & اندازه جمعيت( تعداد يارامترهاى درخواست) & $\mathrm{n}$ \\
\hline 50 & بيشينه تعداد حلقهها & MaxIt \\
\hline 0.5 & لِارامتر تصادفى سازى & $\alpha$ \\
\hline 0.2 & ميزان جذابيت & $\beta$ \\
\hline طبق فرمول & فاصله بين دو كرم أو j & rij \\
\hline طبق فرمول & تغييرات شدت نور & I \\
\hline 1 & ضريب جذب نور & $\lambda$ \\
\hline
\end{tabular}
(Table -8): Parameters used in the firefly algorithm

هدف ما در اين الكوريتم بهينهكردن مقدار PSNR در

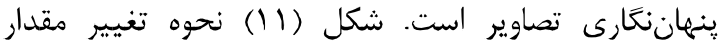

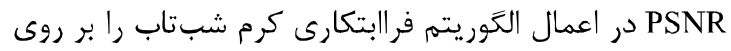
تصوير لنا نشان مى دهد. تا زمانى كه تعداد تكرارها از حد آستانه كمتر است، براى تمامى جمعيت كرم شب تاب، جمعيت به سمت كمان كرم

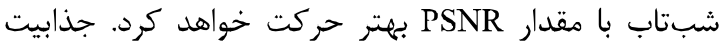

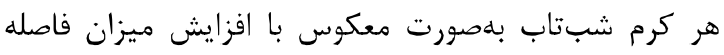

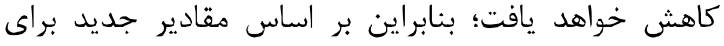

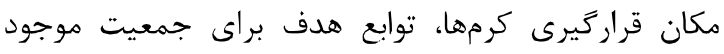

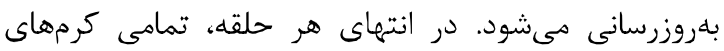
شبتاب بر اساس تابع هدف PSNR مرتب شده و وياسخ 
طبق نتايج بهدستآمده، سه الكوريتم برتر عبارتاند

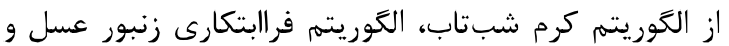
التوريته فرا ابتكارى جستجوى فاخته.

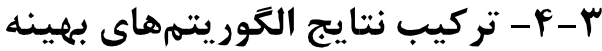

تا اينجا به انتخاب سه الگوريتمى ״رداخته شد كه داراى بالاترين مقدار PSNR و تابع هدف تعريفشده هستند. اين سه الكوريتم عبارتند از الكوريته كرم شبتاب، الكوريتم فرابتكارى زنبور عسل و الكوريتم فرا ابتكارى جستجوى فاخته. از آنجايى كه از ميان روشهاى زنور اعمالشده، الكوريتم

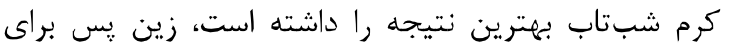
مقايسه نتايج بهدستآمده از نتايج الكوريتم كرم شبتاب رئاب استفاده مى كنيم.
تأثير حذار، ميانخين PSNR بهدستآمده بر روى همه تصاوير فلفل، بابون و لنا در شكل (با) آمده است.

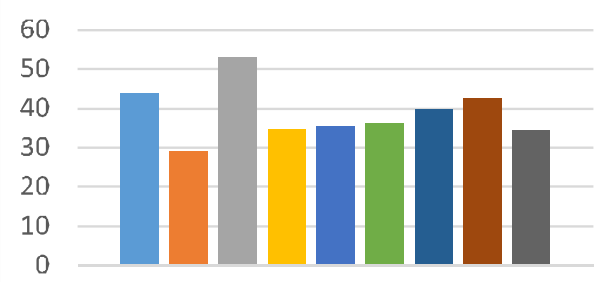

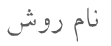

DWTQ $\square$ LSB $\quad$ Firefly $\square$ SA $\quad$ PSO

$\because G A \quad \square C S A \quad A B C \square A C O$

(شكل-r|): مقايسه ميانغين مقدار PSNR بر روى

هر سه تصوير مورد بررسى

(Figure-13): Comparison of the mean value of the PSNR on all three images

(جدول -9) نتايج بهدست آمده از مقايسه PSNR روى تصاوير مختلف در الكَوريتمهاى مورد بررسى در اين مقاله

(Table -9): Results obtained from comparison of PSNR on different images in the algorithms studied in this paper.

\begin{tabular}{|c|c|c|c|c|c|c|c|c|}
\hline نام تصوير & $\mathrm{ACO}$ & $\mathrm{ABC}$ & CSA & \multicolumn{2}{|c|}{ GA } & PSO & Firefly & SA \\
\hline \multirow{2}{*}{ لنا } & \multirow{2}{*}{34.58} & \multirow{2}{*}{44.020} & \multirow{2}{*}{39.68} & $\lambda-10$ & 34.851 & \multirow{2}{*}{37.06} & \multirow{2}{*}{55.72} & \multirow{2}{*}{35.13} \\
\hline & & & & $\lambda=30$ & 34.19 & & & \\
\hline \multirow{2}{*}{ بابون } & \multirow{2}{*}{34.25} & \multirow{2}{*}{40.0256} & \multirow{2}{*}{40.15} & $\lambda=10$ & 36.92 & \multirow{2}{*}{31.28} & \multirow{2}{*}{50.76} & \multirow{2}{*}{34.35} \\
\hline & & & & $\lambda-30$ & 36.01 & & & \\
\hline \multirow{2}{*}{ فلفل } & \multirow{2}{*}{34.55} & \multirow{2}{*}{43.022} & \multirow{2}{*}{40.01} & $\lambda=10$ & 37.21 & \multirow{2}{*}{38.02} & \multirow{2}{*}{52.159} & \multirow{2}{*}{34.86} \\
\hline & & & & $\lambda=30$ & 36.74 & & & \\
\hline ميانخين & 34.46 & 42.35 & 39.94 & - & 35.98 & 35.45 & 52.87 & 34.78 \\
\hline
\end{tabular}

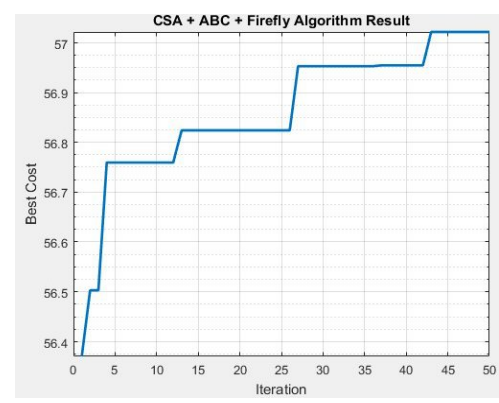

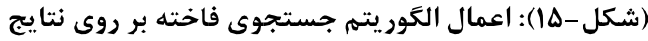

بهدست آمده الكوريتهم زنبور عسل

(Figure-15): Applying the Cuckoo Search Algorithm to the Results of the Bee Algorithm

• تركيب شماره r: كرم شبتاب، جستجوى فاخته،

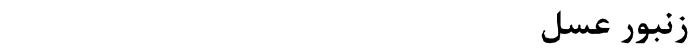

طبق ترتيب كفتدشده، كه در ابتدا الخوريتم كرم شبتاب اعمال و در مرحله بعدى بهترتيب الكوريتمهاى جستجوى فاخته و زنبور عسل اعمال مى دوند.

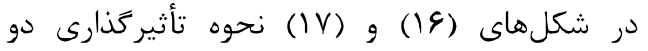

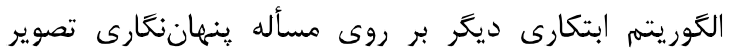
نشان داده شده است.

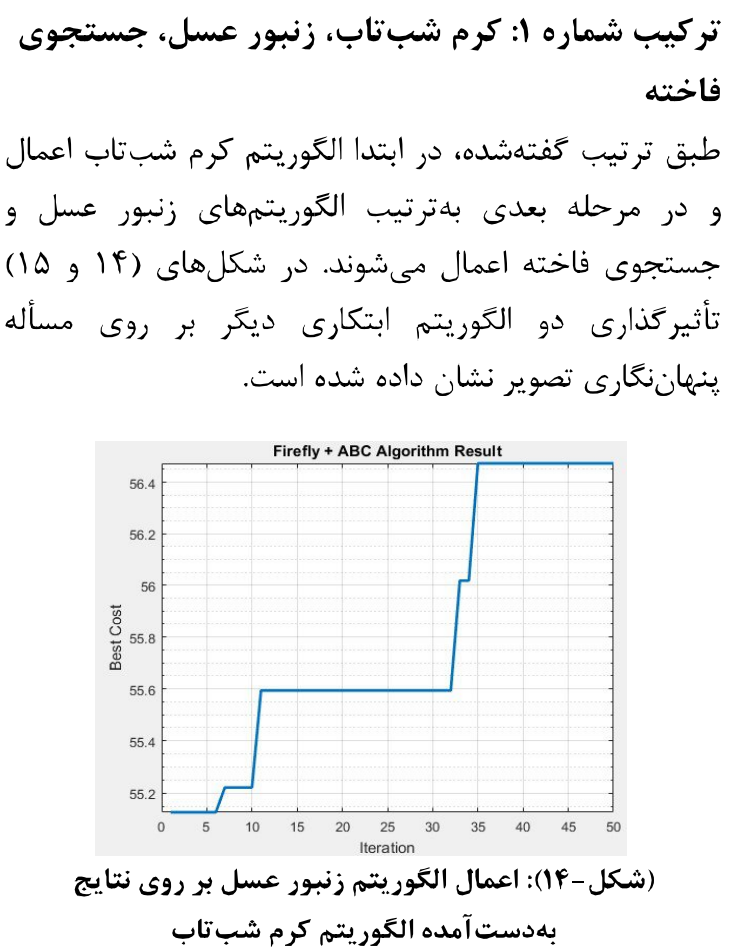

(Figure-14): Applying the Bec Algorithm on the Results of the Firefly Algorithm 


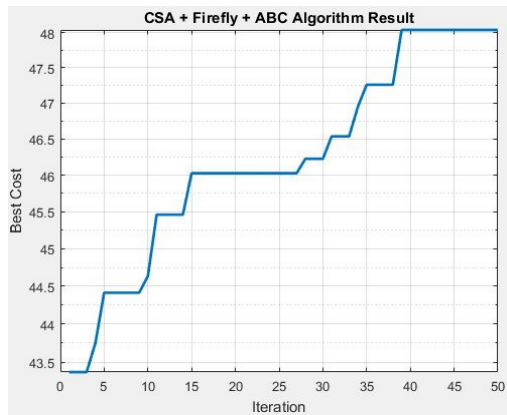

(شكل-19): اعمال الكَوريتم زنبور عسل بر روى نتايج بهدست آمده

الكوريتم كرم شبتاب و جستجوى فاخته در تصوير لنا

(Figure-19): Applying the Bee Algorithm on the Results of the Firefly Algorithm and Cuckoo Search in the Lena Image

$$
\text { • تركيب شماره ff: جستجوى فاخته، زنبور عسل، }
$$

طبق ترتيب كفتهشده، كه در ابتدا الگوريتم جستجوى فاخته اعمال و در مرحله بعدى بهترتيب الكوريتمهاى زنبور عسل و كرم شبتاب اعمال مىشوند. در شكلهاى (·r) و (T) نحوه تأثيرگذارى دو الكوريتم ابتكارى ديخر بر روى مسأله ينهان تحارى تصوير نشان داده شده است.

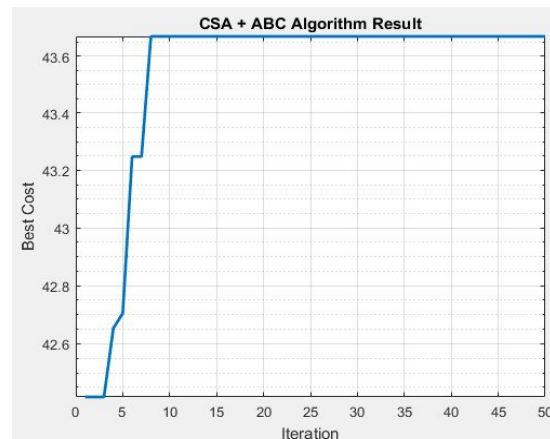

(شكل-_+r): اعمال الغوريتم زنبور عسل بر روى نتايج

بهدست آمده الكوريتم جستجوى فاخته در تصوير لنا

(Figure-20): Applying the Bee Algorithm on the Results of the Cuckoo Search Algorithm in the Lena Image

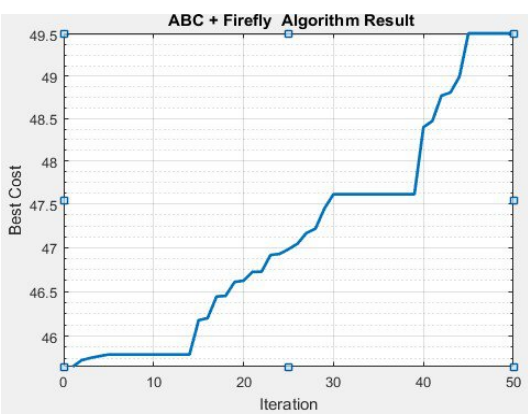

(شكل - (Y): اعمال الكوريتم كرم شبتاب بر روى نتايج

بهدست آمده الكور يتهم زنبور عسل در تصوير لنا

(Figure-21): Applying the firefly algorithm on the results obtained from the bee algorithm in the Lena image

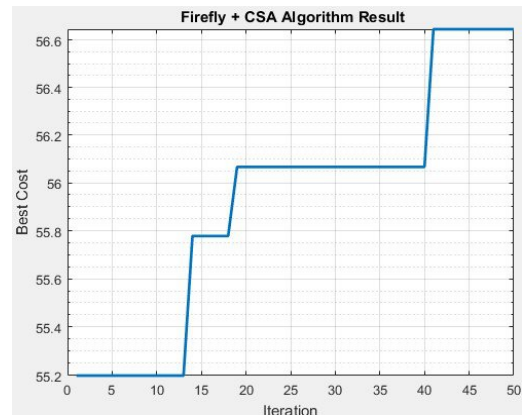

(شكل-19): اعمال الكوريته جستجوى فاخته بر روى نتايج

بهدست آمده الغوريته كرم شبتماب

(Figure-16): Applying the Cuckoo Search Algorithm to the Results of the Firefly Algorithm

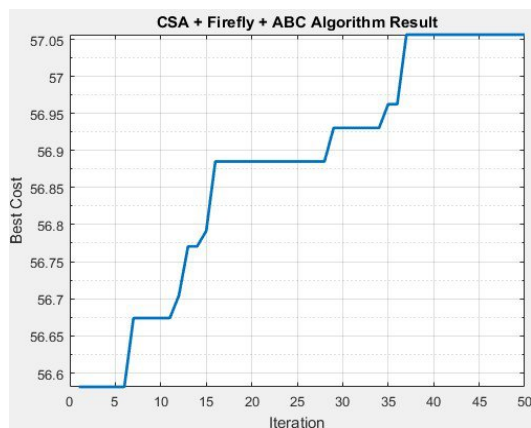

$$
\begin{aligned}
& \text { (شكل - IV): اعمال الكَريتهم زنبور عسل بر روى نتايج } \\
& \text { بلهدست آمده الكوريتم جستجوى فاخته }
\end{aligned}
$$

(Figure-17): Applying the Bec Algorithm on the Results of the Cuckoo Search Algorithm

• تركيب شماره rا: جستجوى فاخته، كرم شبتاب،

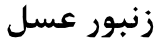

طبق ترتيب كفتهشده، در ابتدا الكَوريتم جستجوى فاخته اعمال و در مرحله بعدى بهترتيب الكوريتمهاى كرم شبتاب و زنبور عسل اعمال مىشوند. در شكلهاى (1) (19) و (19)

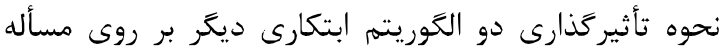
ينهاننخارى تصوير نشان داده شده است.

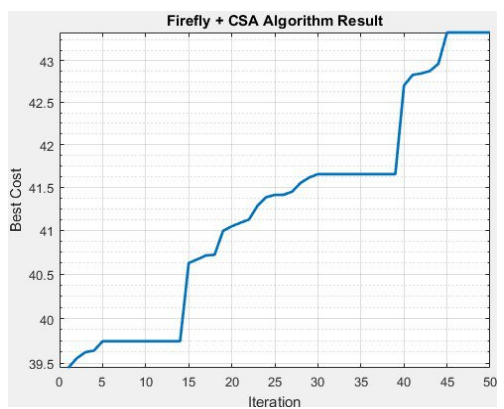

(شكل -11): اعمال الكوريتم كرم شبتاب بر روى نتايج

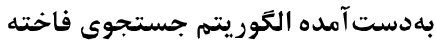

(Figure-18): Applying the firefly algorithm on the results obtained from the Cuckoo search algorithm 


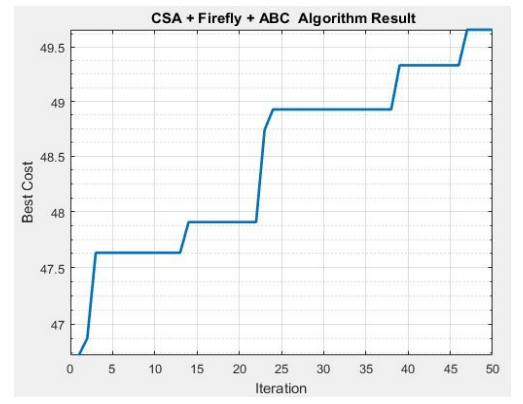

(شكل - Y ( ) : اعمال الكوريتم فاخته بر روى نتايج بهدست آمده

الكوريتم كرم شبتاب در تصوير لنا

(Figure-25): Applying the Cuckoo Algorithm to the Results of the Firefly Algorithm in the Lena Image

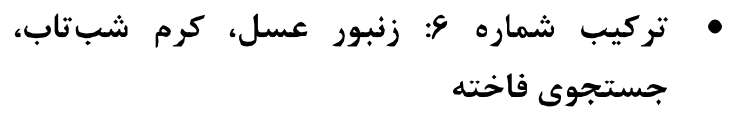

طبق ترتيب كفتهشده، كه در ابتدا الكوريتم زنبور عسل

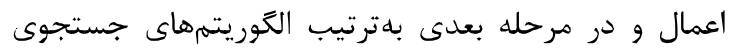

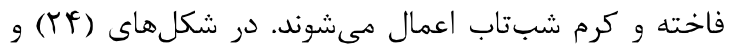

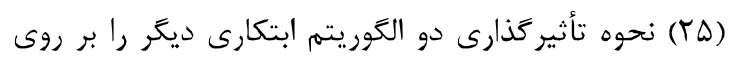
مسأله ينهراننخارى تصوير نشان داده شده است.

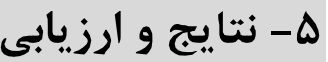

شكل (Yצ) به مقايسه PSNR بهدستآمده از شش مرحله

$$
\text { قبل بر روى تصاوير مختلف مى نيردازد. }
$$

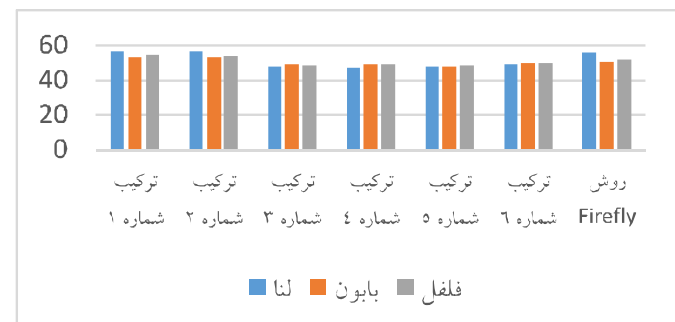

(شكل - (Y)): مقايسه مقدار PSNR در شش مرحله تعريف شده (Figure-26): Compare the PSNR value in the six defined steps

شكل (YV) به مقايسه ميانگين PSNR بهدستآهده

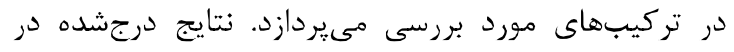

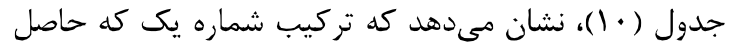
از تركيب بلترتيب الكوريتمهاى كرم شبتاب، زنبور عسل و وديد

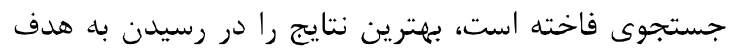
برنامه ايجاد مى كنند كه اين تركيب، ميانكين نسبت سيحنال

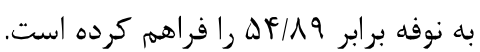
تركيب يادشده در مقايسه با الكوريتمهاى انفرادى بردي

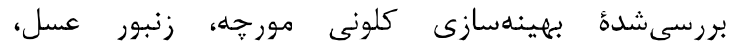
جستجوى فاخته، زُنتيك، حركت ذرات، تبريد شبيدسازى برى
تركيب شماره ه: زنبور عسل، جستجوى فاخته، كرم شبتاب

طبق ترتيب كَتهشده، كه در ابتدا الكوريتم زنبور عسل اعمال و در مرحله بعدى بلهترتيب الكوريتشهاى جستجوى

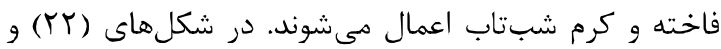

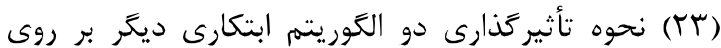
مسأله ينهان:خارى تصوير نشان داده شده است.

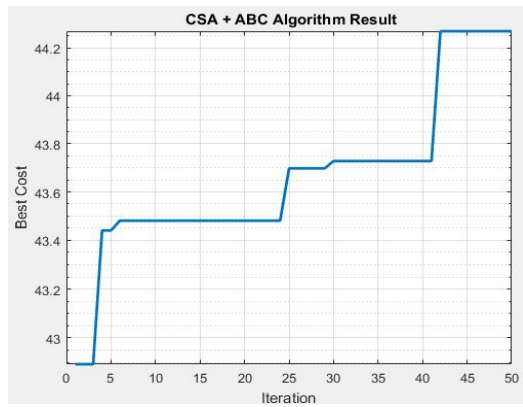

(شكل - (YY): اعمال الكوريتم فاخته بر روى نتايج بلهدست آمده الكوريتم زنبور عسل در تصوير لنا

(Figure-22): Applying the Cuckoo Algorithm to the Results of the Bee Algorithm in the Lena Image

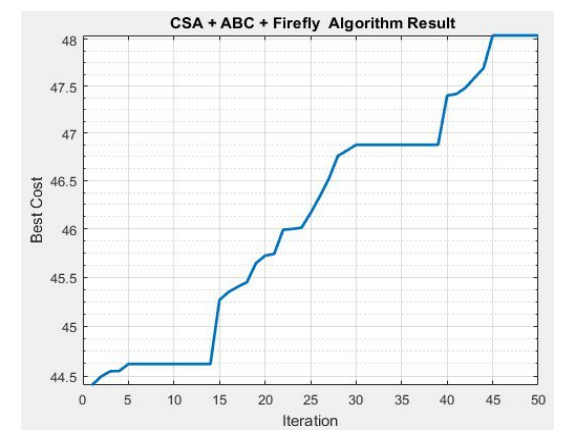

(شكل - rr): اعمال الكوريتم كرم شبتاب بر روى نتايج

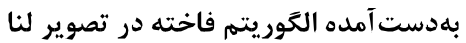

(Figure-23): Applying the firefly algorithm on the results obtained from the Cuckoo algorithm in the Lena image

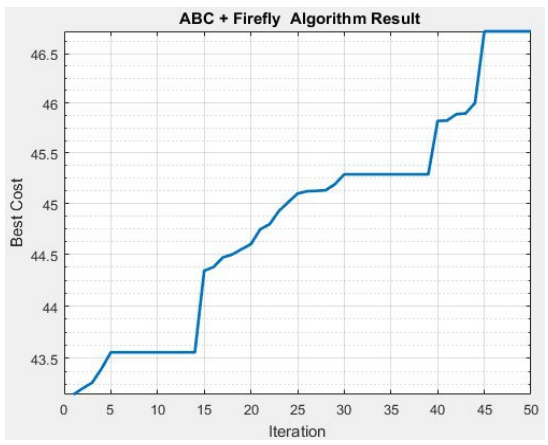

(شكل - (YF): اعمال الكوريته كرم شبتاب بر روى نتايج

بهدست آمده الكوريتهم زنبور عسل در تصوير لنا

(Figure-24): Applying the firefly algorithm on the results obtained from the Bee algorithm Lena image 
يثوهشهاى ديخر مقايسه شده است [32]، [33]، [34]، [35]؛

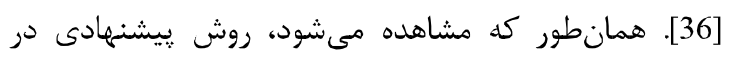

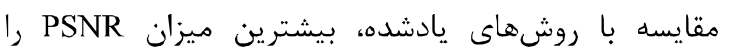

$$
\text { حاصل كرده است. }
$$

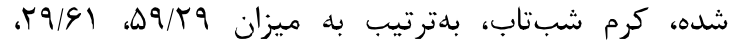
r مقدار PSNR را ارائه مى كند. در جدول (11)، مقدار PSNR يس از إنس اعمال روش ييشنهادى و ساير روشهاى اعمالشده بر روى تصوير لنا در

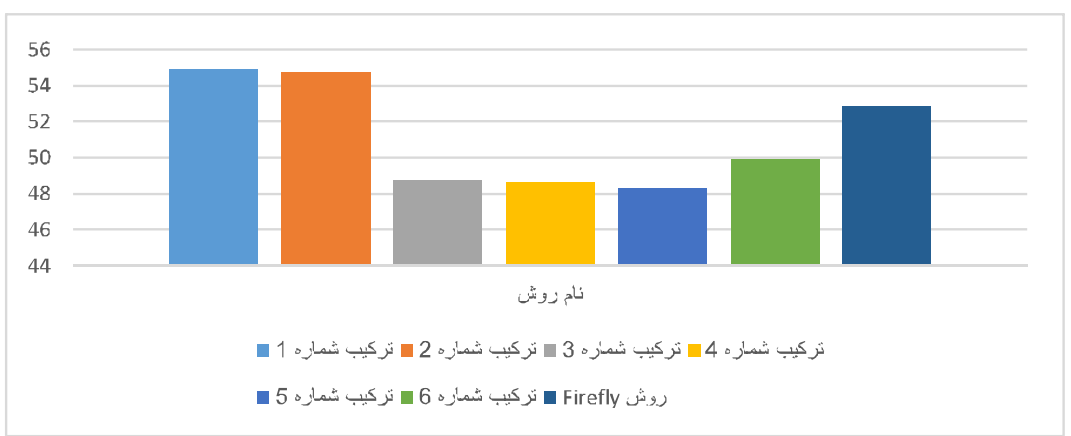

(شكل - (YV) : مقايسه ميانگين PSNR در روشهاى مورد بررسى :

(Figure-27): Comparison of the mean PSNR in the investigated methods

(جدول -•(1): مقدار PSNR يس از اعمال تركيبهاى مختلف بر روى تصاوير (Table-10): The amount of PSNR after applying different combinations on the images

\begin{tabular}{|c|c|c|c|c|c|c|c|}
\hline نام تصوير & شمارهيب & شماره r & شماره ب & شماره F & شماره هـ & شماره \& & Firefly \\
\hline لنا & 57.12 & 57.02 & 48.03 & 49.5 & 48.01 & 49.6 & 55.72 \\
\hline بابون & 53.04 & 53.1 & 49.3 & 49.18 & 48.1 & 50.18 & 50.76 \\
\hline فلفل & 54.52 & 54.23 & 49.068 & 49.16 & 48.9 & 50.09 & 52.159 \\
\hline ميانغين & 54.89 & 54.78 & 48.80 & 49.28 & 48.34 & 49.96 & 52.88 \\
\hline
\end{tabular}

(جدول -11): مقايسه مقدار PSNR يس از اعمال روشهاى مختلف بر روى تصوير لنا در يثوهشهاى مختلف (Table-11): Compare the amount of PSNR after applying different methods to the Lena image in different research

\begin{tabular}{|c|c|c|c|c|c|c|}
\hline الكوريتمهاى & ريشنهادى روش & Wang & Yang & Liao & Mehdi & Zhaotong \\
\hline ميزان PSNR يس اعمال الكَوريتم & 57.12 & 44.1 & 38.24 & 41.48 & 39.09 & 42.74 \\
\hline
\end{tabular}

مختلف آنها مورد بررسى قرار گَرفت. سه الكَريتهم انتخابشده عبارتاند از الكَوريتم كرم شبتاب، الكَوريتم جستجوى فاخته و الكوريتم بهينهسازى زنبور عسل بابل

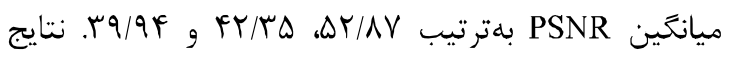
نشان مى مهد كه تركيب شماره يك كه حاصل از تركيب بهترتيب الخوريتمهاى كرم شبتاب، زنبور عسل و جستجوى

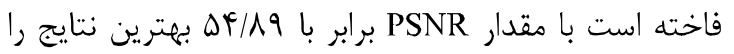
در رسيدن به ياسخ بهينه در مقايسه با تركيبهاى شماره ؟، r، f (
و- نتيجه كيرى در اين مقاله يك روش مقاوم با درجه امنيتى بالا براى ينهاننارى تصاوير ارائه شد. روش ييشنهادى در رمزنغارى تصاوير بهمنظور بهببود مقدار PSNR و دستيابى به ماتريس جايخزينى بهينه از الكوريتمهاى فرا ابتكارى استفاده مى كند. ابتدا الكوريتمهاى معروف فرابتكارى در رمزنغارى تصاوير مورد استفاده قرار گرفتهاند و بهتنهايى بر روى داديد دادهاى

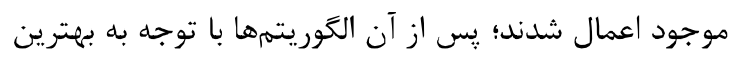

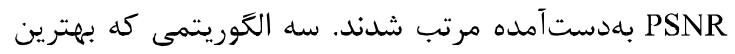

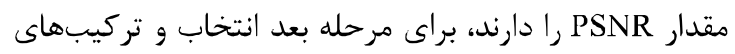


[10] F. Sadeghi, M. K. Rafsanjani, and F. Z. Kermani, "Hiding Information in Image by Compound Meta-Heuristic Algorithm PSO-SA," Int. J. Compute Sci. Artif. Intell, vol. 3, no. 4, p. 125, 2013.

[11] K. Akshyata and 1. Jain, "Data Hiding and Security using Steganography", International Journal of Engineering and Management Research, 2017.

[12] E. T. Zghaer and S. H. Hashem, "Ant Colony Optimization To Enhance Image Steganography", International Journal of Emerging Trends and Technology in Computer Science (IJETTCS), 2017.

[13] A. Miri, K. Faez, "Adaptive image steganography based on transform domain via genetic algorithm", Optik, vol. 145, pp.158-168.

[14] K. Loukhaoukha, J.-Y. Chouinard, and M. H. Taieb, "Optimal image watermarking algorithm based on LWT-SVD via multi-objective ant colony optimization," J. Inf. Hiding Multimed. Signal Process., vol. 2, no. 4, pp. 303-319, 2011.

[15] J. S. Lee, J.-W. Wang, and K.-Y. Giang, " $\Lambda$ new image watermarking scheme using multiobjective bees algorithm," Appl. Math. Inf. Sci., vol. 8 , no. 6 , p. 2945,2014

[16] F. G. Mohammadi and M. S. Abadeh, "Image steganalysis using a bee colony based feature selection algorithm," Eng. Appl. Artif. Intell., vol. 31, pp. 35-43, 2014.

[17] M. Ali and C. W. Ahn, "An optimal image watermarking approach through cuckoo search algorithm in wavelet domain," Int. J. Syst. Assur. Eng. Manag., pp. 1-10, 2014.

[18] Y. H. Chen and H. C. Huang, "Reversible Image Watermarking Based on Genetic Algorithm," in Intelligent Information Hiding and Multimedia Signal Processing (IIII-MSP), 2014 Tenth International Conference on, 2014, pp. 21-24.

[19] a L. Brazil, a Sanchez, a Conci, and N. Behlilovic, "Hybridizing genetic algorithms and path relinking for steganography," ELMAR 2011 Proc., no. September, pp. 285-288, 2011.

[20] M. Nosrati, A. Hanani, and R. Karimi, "Steganography in Image Segments Using Genetic Algorithm," in 2015 Fifth International Conference on Advanced Computing Communication Technologies, 2015, pp. 102107.

[21] B. Lei, F. Zhou, E.-L. Tan, D. Ni, H. Lei, S. Chen, and T. Wang, "Optimal and secure audio watermarking scheme based on self-adaptive particle swarm optimization and quaternion wavelet transform," Signal Processing, vol. 113, pp. 80-94, 2015.

$$
\begin{aligned}
& \text { تركيب كفتهشده در مقايسه با الخوريتمهاى انفرادى }
\end{aligned}
$$

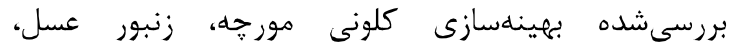

$$
\begin{aligned}
& \text { جستجوى فاخته، رنتيك، حركت ذرات، تبريد }
\end{aligned}
$$

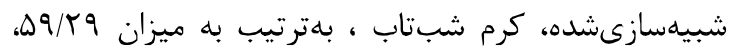

$$
\begin{aligned}
& \text { I } \\
& \text { بهبود در مقدار PSNR را ارائه مى كند. }
\end{aligned}
$$

\section{7- References}

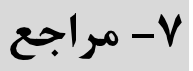

$$
\begin{aligned}
& \text { [1] شمع عليزاده بايى محمدعلى، "بررسى الگوريتمهاى }
\end{aligned}
$$

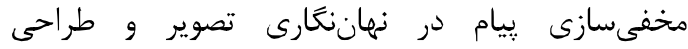

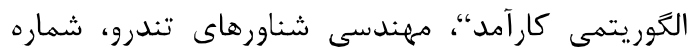

$$
\begin{aligned}
& \text { Y }
\end{aligned}
$$

[1] M. SH. Alizadeh, "Evaluation of message hiding algorithms in image steganography and efficient algorithm design", High Speed Craft, Vol. 52, pp. 42-30, 2018.

[2] X. Zhang, Z. Zhao, and J. Wang, "Chaotic image encryption based on circular substitution box and key stream buffer", Signal Process. Image Commun., vol. 29, no. 8, pp. 902-913, 2014.

[3] M. Hussain and M. Hussain, "A Survey of Image Steganography Techniques," vol. 54, pp. 113124,2013

[4] A.Benoraira, K. Benmahammed, and N. Boucenna, "Blind image watermarking technique based on differential embedding in DWT and DCT domains," EURASIP J. Adv. Signal Process., vol. 2015, no. 1, pp. 1-11, 2015.

[5] H. Tao, L. Chongmin, J. M. Zain, and A. N. Abdalla, "Robust image watermarking theories and techniques: A review," J. Appl. Res. Technol., vol. 12, no. 1, pp. 122-138, 2014.

[6] N. A. Abbas, "Image watermark detection techniques using quadtrees," Appl. Compute Informatics, vol. 11, no. 2, pp. 102-115, 2015.

[7] M. Keyvanpour and F. M. Bayat, "Blind image watermarking method based on chaotic key and dynamic coefficient quantization in the \{DWT\} domain," Math. Compute. Model, vol. 58, no. 1-2, pp. 56-67, 2013.

[8] Z. Xie and X. Wang, "A Heuristic Feature Combination Selection Method in Fusion Detection of JPEG Stegoimages," in 2012 Fourth International Conference on Multimedia Information Networking and Security, 2012, pp. $220-224$

[9] M. Kiamini, S. Fazli , " A High Performance Steganographic Method using JPEG and PSO Algorithm," IEEE, 2008. 
[34] X. Liao, QY. Wen, ZL. Zhao, "A novel steganographic method with four-pixel differencing and modulus function", Fundam Informaticae, Vol. 118, pp. 281-289, 2012.

[35] M. Hussain, AWA. Wahab, ATS. Ho, "A data hiding scheme using parity-bit pixel value differencing and improved rightmost digit replacement", Signal Pro- cess Image Commun, Vol. 50, pp.44-57, 2017.

[36] Li. Zhaotong, Hc.Ying, "Steganography with pixcl-value differencing and modulus function based on PSO", Journal of Information Security and Applications, vol. 43, pp. 47-52, 2018.

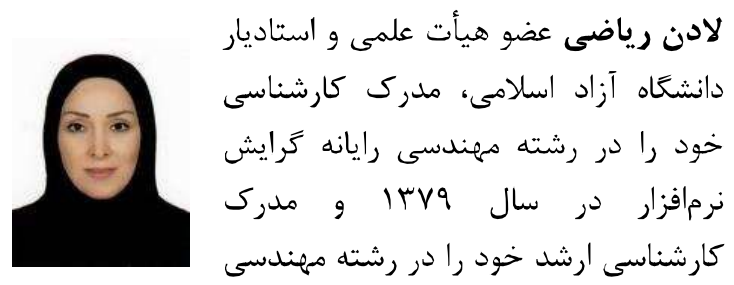

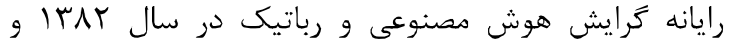
مدرك دكتراى خود را در رشته مديريت فناورى اطلاعات كرايش كسب و كار هوشمند در سال هوبا از دانشعاه آزاد اسلامى دريافت كردهاند. زمينهاى زيزوهشى مورد علاقه ايشان بردازش تصوير، هوش تجارى، سامانهاى اطلاعات مديريتى و آموزش الكترونيكى است. نشانى رايانامه ايشان عبارت است ازئ

Iriazi@iauec.ac.ir

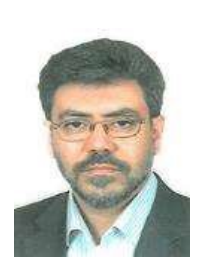

عليرضا هورابراهيمى عضو هيأت علمى و

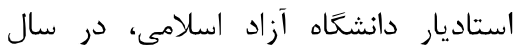

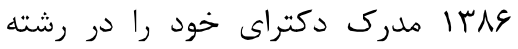

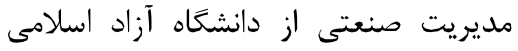

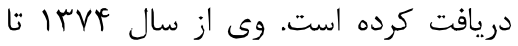
كنون به امر تدريس در دانشغاههاى كشور اشتغال داشتهاند

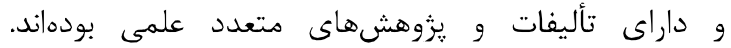
زمينههاى يزوهشى مورد علاقه ايشان امنيت، الخوريتمهاى فرابتكارى و دادهكاوى است.

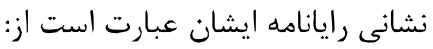
poorebrahimi@gmail.com

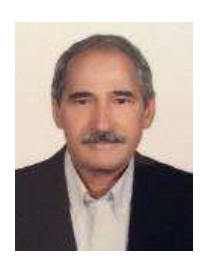

$$
\text { محمود البرزى عضو هيأت علمى والم وانو }
$$

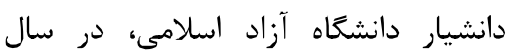$$
\text { هVD }
$$

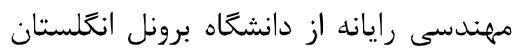

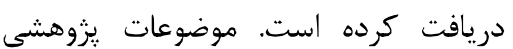

[22] X. Li and J. Wang, "A steganographic method based upon $\{J P E G\}$ and particle swarm optimization algorithm," Inf. Sci. (Ny)., vol. 177, no. 15, pp. 3099-3109, 2007.

[23] G. S. Lin, Y. T. Chang, and W. N. Lie, "A Framework of Enhancing Image Steganography With Picture Quality Optimization and AntiSteganalysis Based on Simulated Annealing Algorithm," IEEE Trans. Multimed., vol. 12, no. 5, pp. 345-357, Aug. 2010.

[24] A. Mishra, C. Agarwal, A. Sharma, and P. Bedi, "Optimized gray-scale image watermarking using DWT--SVD and Firefly Algorithm," Expert Syst. Appl., vol. 41, no. 17, pp. 78587867,2014

[25] A. Miri, K. Faez, "Adaptive image steganography based on transform domain via genetic algorithm", Optik, vol. 145, pp.158-168.

[26] S. Hemalatha, U. D. Acharya, and A. Renuka, "Wavelet Transform Based Steganography Technique to Hide Audio Signals in Image," Procedia Comput. Sci., vol. 47, pp. 272-281, 2015.

[27] M. Nosrati, A. Hanani, and R. Karimi, "Steganography in Image Segments Using Genetic Algorithm," in 2015 Fifth International Conference on Advanced Computing Communication Technologies, 2015, pp. 102107.

[28] Z. Li, Y. Hi, "Steganography with pixel-value differencing and modulus function based on PSO," Information Security and Applications, vol.43, pp. 47-52, 2018.

[29] F. G. Mohammadi , H. sajedi, "Region based Image Steganalysis using Artificial Bee Colony," Visual Communication and Image Representation, vol 14, pp. 214-226, 2017.

[30] S.I. Nipanikar, V. H. Deepthi, N. Kulkarni, "A sparse representation based image steganography using Particle Swarm Optimization and wavelet transform," Alexandria Engineering, vol. 57, pp. 2343-2356, 2018.

[31] A. Miri, k. Faez, "Adaptive image steganography based on transform domain via genetic algorithm," Optik, vol. 145, pp. 158$168,2017$.

[32] CM.Wang, NI. Wu, CS. Tsai, "A high quality steganographic method with pixel-value differencing and modulus function", J Syst Softw, Vol. 81, pp.150-158, 2008.

[33] CH. Yang, SJ. Wang, C. Weng, "Capacityraising steganography using multi- -pixel differencing and pixel-value shifting operations", Fundam Informaticae, Vol. 98, pp.321-336, 2010. 


$$
\begin{aligned}
& \text { مورد علاقه ايشان، هوش مصنوعى - شبكههاى عصبى، }
\end{aligned}
$$

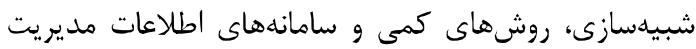

$$
\begin{aligned}
& \text { ي بيشرفته است. } \\
& \text { نشانى رايانامه ايشان عبارت است ازز: } \\
& \text { mahmood_alborzi@yahoo.com } \\
& \text { رضا رادفر عضو هيأت علمى و استاد }
\end{aligned}
$$

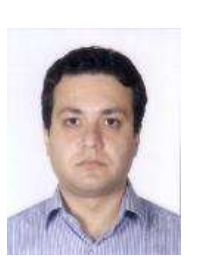
r.radfar@srbiau.ac.ir

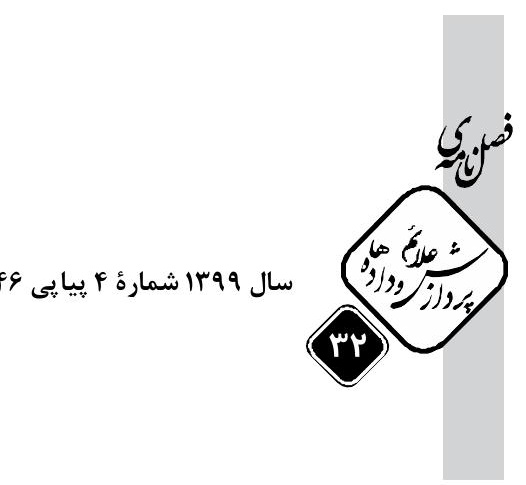

